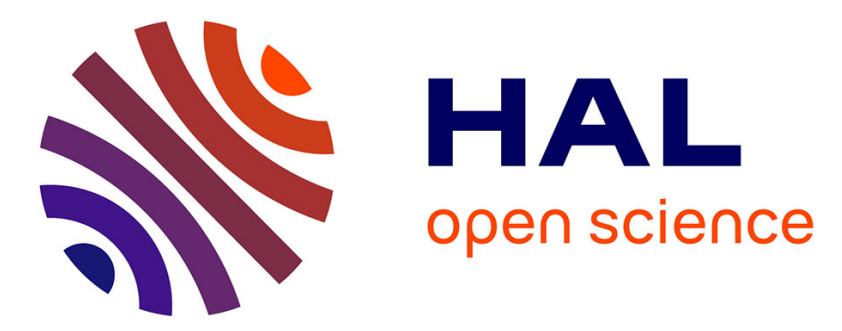

\title{
A Catalytic Domino Approach toward Oxo-Alkyl Carbonates and Polycarbonates from CO 2 , Propargylic Alcohols, and (Mono- and Di-)Alcohols
}

Charlene Ngassam Tounzoua, Bruno Grignard, Antoine Brege, Christine Jérôme, Thierry Tassaing, Raphael Mereau, Christophe Detrembleur

\section{To cite this version:}

Charlene Ngassam Tounzoua, Bruno Grignard, Antoine Brege, Christine Jérôme, Thierry Tassaing, et al.. A Catalytic Domino Approach toward Oxo-Alkyl Carbonates and Polycarbonates from CO 2 , Propargylic Alcohols, and (Mono- and Di-)Alcohols. ACS Sustainable Chemistry \& Engineering, 2020, 8 (26), pp.9698-9710. 10.1021/acssuschemeng.0c01787 . hal-02990794

\author{
HAL Id: hal-02990794 \\ https://hal.science/hal-02990794
}

Submitted on 17 Nov 2020

HAL is a multi-disciplinary open access archive for the deposit and dissemination of scientific research documents, whether they are published or not. The documents may come from teaching and research institutions in France or abroad, or from public or private research centers.
L'archive ouverte pluridisciplinaire HAL, est destinée au dépôt et à la diffusion de documents scientifiques de niveau recherche, publiés ou non, émanant des établissements d'enseignement et de recherche français ou étrangers, des laboratoires publics ou privés. 


\title{
A catalytic domino approach towards oxo-alkyl
}

carbonates and polycarbonates from $\mathrm{CO}_{2}$,

\section{propargylic alcohols and (mono- and di-) alcohols}

Charlene G. NGASSAM TOUNZOUA, ${ }^{a}$ Bruno GRIGNARD, ${ }^{a}$ Antoine BREGE, ${ }^{a}$ Christine JEROME,${ }^{a}$ Thierry TASSAING, ${ }^{b}$ Raphael MEREAU, ${ }^{b}$ Christophe DETREMBLEUR ${ }^{a} *$

${ }^{a}$ Center for Education and Research on Macromolecules (CERM), CESAM Research Unit, University of Liege, Allée de la Chimie, B6a, 4000 Liège (Belgium).

* Corresponding author : christophe.detrembleur@uliege.be

${ }^{\mathrm{b}}$ Institut des Sciences Moléculaires, UMR 5255 CNRS Université Bordeaux, 351, Cours de la Libération, F-33405 Talence Cedex, France

KEYWORDS. $\mathrm{CO}_{2}$, polycarbonates, exovinylene cyclic carbonate, catalysis

\begin{abstract}
.
We have explored the domino reaction between propargylic alcohols, carbon dioxide and various alcohols with the double objective to prepare oxo-alkylcarbonates with a high yield and selectivity under mild conditions and to extend the process to the synthesis of phosgene-free polycarbonates. We first searched for a common catalytic system that was highly selective for the two reactions involved in the domino process, i.e. the cycloaddition of $\mathrm{CO}_{2}$ to propargylic
\end{abstract}


alcohol to yield $\alpha$-alkylidene cyclic carbonate $(\alpha C C)$, and the alcoholysis of $\alpha \mathrm{CC}$ to furnish the oxo-alkylcarbonate. Kinetics studies monitored by operando IR spectroscopy and supported by ${ }^{1} \mathrm{H}-\mathrm{NMR}$ analyses and DFT modeling have permitted to identify an efficient binary catalytic system composed of a combination of tetrabutylammonium phenolate [TBA][OPh] and silver iodide (AgI) (or copper iodide (CuI)) and to understand its action mode. The [TBA][OPh]/AgI catalytic system $(5 \mathrm{~mol} \%)$ was then successfully implemented for the selective preparation of a range of oxo-alkylcarbonates by the domino reaction with alcohols and propargylic alcohols of different structures. Most of these oxo-alkylcarbonates were produced at a high yield ( $\geq 97 \%$ ) under mild operating conditions, i.e. at $60{ }^{\circ} \mathrm{C}$ and 1 bar of $\mathrm{CO}_{2}$. The one-pot synthesis of various poly( $\beta$-oxocarbonate)s from bis(propargylic alcohol)s, diols and $\mathrm{CO}_{2}$ was finally investigated and the best operating conditions ([TBA][OPh]/AgI (10 mol\%), $60{ }^{\circ} \mathrm{C}, 15$ bar) afforded polycarbonate oligomers with weight-average molar masses of 4,300 g/mol. Although the system should be optimized to produce longer polymer chains, this process offers a new phosgene-free alternative to the synthesis of functional polycarbonates (poly(oxo-carbonate)s) under mild conditions.

\section{INTRODUCTION.}

Today, the upsurge in $\mathrm{CO}_{2}$ utilization as renewable $\mathrm{C} 1$ feedstock has opened avenues in modern chemistry for the synthesis of a large diversity of (novel) organic scaffolds (e.g. organic carbonates, $^{1-5}$ carbamates $^{6,7}$, oxazolidones, ${ }^{5,8-11}$ carboxylic acids, ${ }^{12-14}$ etc.) and polymers ${ }^{15}$ (e.g. polycarbonates, ${ }^{16-20}$ polyurethanes, ${ }^{21-24}$ polyesters, ${ }^{25}$ polyureas ${ }^{26,27}$ ). Among them, $\alpha$-alkylidene 5-membered cyclic carbonates $(\alpha \mathrm{CCs})$ are emerging as a novel class of $\mathrm{CO}_{2}$-sourced building blocks highlighted by BASF as promising molecules for organic and polymer chemistries. ${ }^{28}$ 
They are typically synthesized by a $100 \%$ atom efficiency carboxylative coupling of $\mathrm{CO}_{2}$ to propargylic alcohols, ${ }^{29-33}$ with some of them that are easily accessible from acetylene and industrial formaldehyde waste. $^{34}$ Unlike the conventional 5-membered cyclic carbonates, $\alpha$ alkylidene 5-membered cyclic carbonates display a remarkable reactivity towards amines, alcohols and thiols to afford urethanes ${ }^{35}$ (oxazolidones or $\beta$-oxo-carbamates ${ }^{36,37}$ ), $\beta$-oxoalkylcarbonates, ${ }^{38,39}$ and thiocarbonates or sulfur-containing tetrasubstituted ethylene carbonates, ${ }^{40,41}$ respectively. The presence of the exocyclic olefin increases the ring-strain of the molecule and ensures the selective ring-opening by the nucleophiles with the formation of an enol intermediate which tautomerizes into a ketone, thus acting as the driving force for the reaction. The unique chemical features of $\alpha \mathrm{CC}$ s were exploited by our group to pioneer a novel route to $\mathrm{CO}_{2}$-sourced polycarbonates with unprecedented microstructures ${ }^{40}$ that already showed relevance as solid electrolytes for Li-ion batteries. ${ }^{42,43}$ In contrast to the conventional synthesis of $\mathrm{CO}_{2}$-sourced polycarbonates by the direct ring-opening copolymerization of $\mathrm{CO}_{2}$ with epoxides, ${ }^{44-47}$ our approach focused on the polyaddition of bis( $\alpha$-alkylidene cyclic carbonate)s (bis- $\alpha \mathrm{CCs}$ ) to diols in the presence of an organobase as catalyst to afford regioregular and defects-free poly( $\beta$-oxo-carbonate $)$ s at room temperature. Early this year, Schaub engineered a novel synthetic protocol to provide bis $\alpha \mathrm{CCs}$ and also demonstrated their utility for the fabrication of low molar mass poly( $\beta$-oxo-carbonate)s $(\mathrm{Mn} \sim 2,000 \mathrm{~g} / \mathrm{mol}) .{ }^{48}$ However, the synthetic routes to bis $\alpha \mathrm{CCs}$ are still tedious with demanding purification procedures. To push away these boundaries, we introduce in this work a novel domino terpolymerization approach to produce poly( $\beta$-oxo-carbonate)s from a mixture of $\mathrm{CO}_{2}$, bispropargylic alcohol and diols (Scheme 1b), some of them being selected for their ease of production from lignin biomass. If many publications focused on the one-pot domino synthesis of oxazolidinones and oxopropyl 
carbamates from $\mathrm{CO}_{2}$, propargylic alcohols and amines ${ }^{49-54}$, only few examples reported the preparation of oxoalkyl carbonates by reacting propargylic alcohols, $\mathrm{CO}_{2}$ and alcohols (Scheme 1a). The challenge lies in the identification of suitable catalysts capable of fixing $\mathrm{CO}_{2}$ to propargylic alcohols to in-situ form $\alpha \mathrm{CC}$ in a selective manner and to promote their alcoholysis. Song reported on the synthesis of oxoalkyl carbonates with yields of $22-76 \%$ using DBU/Zn salts $(40: 20 \mathrm{~mol} \%)$ as catalytic systems at $80{ }^{\circ} \mathrm{C}, 10$ bar in $16 \mathrm{~h} .{ }^{55} \mathrm{Hu}$ obtained yields up to $99 \%$ with $\mathrm{AgCl} /$ butylmethylimidazolium acetate ([BMIm][OAc]) binary catalytic systems. However the ionic liquid was added in large amount $(100 \mathrm{~mol} \%)$ to promote the reaction at room temperature and atmospheric $\mathrm{CO}_{2}$ pressure. ${ }^{39} \mathrm{He}$ 's group used a combination of $\mathrm{Ag}_{2} \mathrm{CO}_{3}$ and $\mathrm{PPh}_{3}$ to catalyze the formation of oxoalkyl carbonates scaffolds with yields of $62-78 \%$. Working with a 0.5 eq excess in the alcohol was required to obtain higher yields $(98 \%) .{ }^{56}$ Zhang reported high yields of $81-93 \%$ and a large product scope using a silver sulfadiazine/EtNBr (5 mol\%) dual system at $1 \mathrm{bar}, 80{ }^{\circ} \mathrm{C}$ for $24 \mathrm{~h} .^{57,58}$ This later system suffers from the multi-step synthesis of sulfadiazine that is not a straightforward procedure. Although different catalytic systems exist to provide simple $\alpha \mathrm{CCs}$ and oxoalkyl carbonates, none of them has been utilized for both the quantitative synthesis of bis $\alpha \mathrm{CCs}$ and their in-situ transformation into poly( $\beta$-oxocarbonate)s in a cascade reaction. In addition, as previously exemplified, none of them supported the features needed to respond to the requirements of a step-growth polymerization process that is extremely sensitive to the stoichiometry of the reaction. The bis $\alpha \mathrm{CCs}$ intermediate produced in-situ by carboxylative cycloaddition of $\mathrm{CO}_{2}$ to bis(propargylic alcohol) will be directly involved in the polyaddition to the diol. Any side reactions will therefore result in a deviation from the perfect stoichiometry and cause the termination of the domino terpolymerization. To pursue our goal, it 
is therefore crucial to identify operating conditions and a catalytic system compatible for both steps, i.e. the selective formation of bis $\alpha \mathrm{CC}$ and its copolymerization with the diol.

In this work, we have developed a novel binary catalyst and evaluated its activity and selectivity on model compounds. Kinetic insights via operando FT-IR spectroscopy, correlated to mechanistic DFT calculations enabled us to understand and rationalize the mode of action of the catalyst. We then used it to selectively synthesize oxo-alkylcarbonates of different structures by the domino reaction between $\mathrm{CO}_{2}$, propargylic alcohols and mono-alcohols. Finally this process was exploited for the preparation of PCs under mild operative conditions.

\section{(a) Cascade synthesis of oxo-alkylcarbonates}

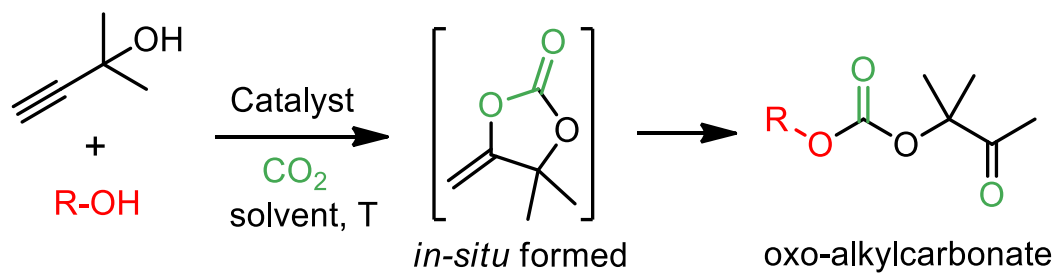

\section{(b) Cascade synthesis of poly( $\beta$-oxo-carbonate)s}

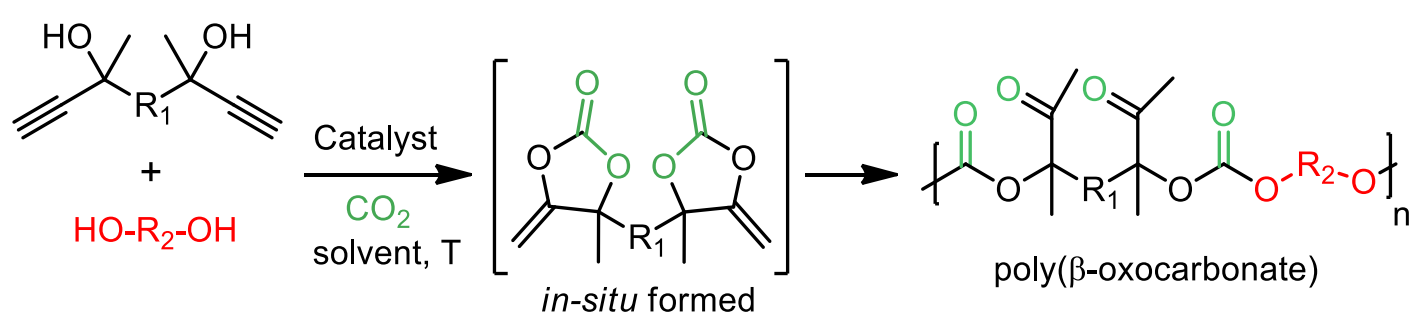

Scheme 1. One pot domino synthesis of (a) oxo-alkylcarbonates and (b) poly( $\beta$-oxo-carbonate)s

\section{RESULTS AND DISCUSSION}

Catalyst design and optimization of the reaction parameters. Model carboxylative coupling reactions of $\mathrm{CO}_{2}$ with 2-methyl-3-butyn-2-ol to provide $\alpha \mathrm{CC}$ were first screened (Scheme 2). We selected tetrabutylammonium phenolate $([\mathrm{TBA}][\mathrm{OPh}])$ as the organocatalyst as we 
previously demonstrated its high efficiency for the envisioned reaction under moderate conditions. ${ }^{59}$ This activity resulted from a good compromise between ion-pair separation controlled by steric effect and the basicity of the anion as evidenced in a previous benchmarking study. ${ }^{59}$ Moreover, it is easily prepared from cheap phenol, a bio-based product derived from the fractionation of lignin. ${ }^{60}$

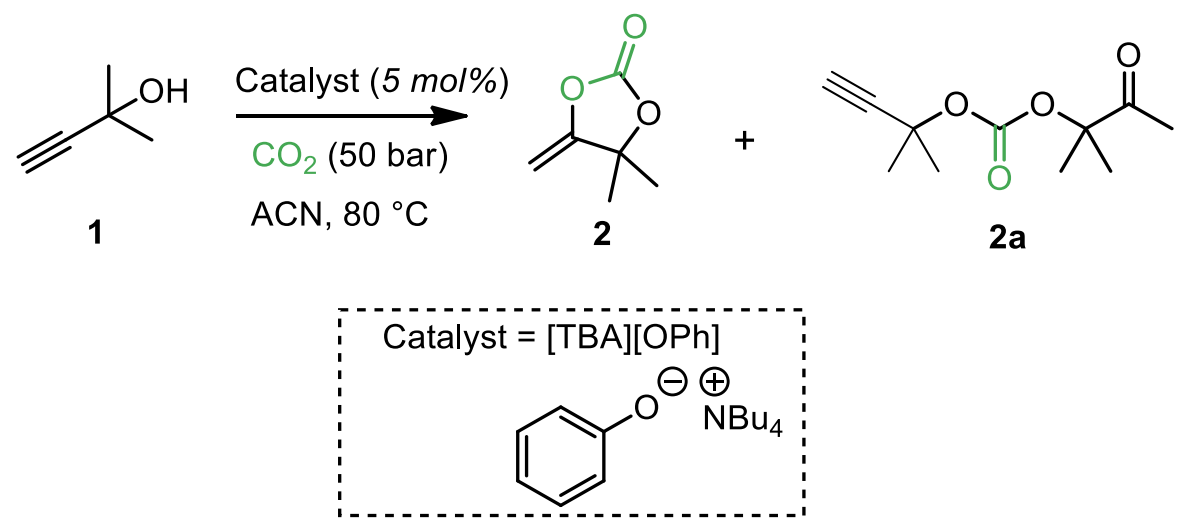

Scheme 2. Coupling of $\mathrm{CO}_{2}$ to 2-methyl-3-butyn-2-ol.

The model reaction was carried out at 50 bar and $80{ }^{\circ} \mathrm{C}$ in acetonitrile with a low catalyst loading (5 mol\%). Under these conditions, the expected $\alpha \mathrm{CCs} 2$ was produced with $90 \%$ yield in only 1 h (Table 1, entry 1). However, the main side reaction observed was the formation of the linear oxo-carbonate 2a by the addition of the propargylic alcohol to $\alpha \mathrm{CCs}$. To extend the use of this catalytic system for the targeted domino reaction and prevent this side reaction, an optimization of both the reaction conditions and the catalyst structure was required.

Table 1. Influence of the temperature on the carboxylative cyclisation of $\mathrm{CO}_{2}$ with 2-methyl-3butyn-2-ol catalyzed by [TBA][OPh]
Entry
Temp.
Reaction time
Conv. of 1
Selectivity for 2 


\begin{tabular}{ccccc}
\hline & $\left({ }^{\circ} \mathbf{C}\right)$ & $(\mathbf{h})$ & $(\%)$ & $(\%)$ \\
\hline 1 & 80 & 1 & 100 & 90 \\
3 & 60 & 1 & 20 & 99 \\
4 & 60 & 6 & 100 & 99 \\
5 & 40 & 1 & 6 & 99 \\
\hline
\end{tabular}

Conditions: 2-methyl-3-butyn-2-ol (2 mL, 0.02061mol), [TBA][OPh] (5 mol\%), acetonitrile (2 $m L), \mathrm{CO}_{2}(50 \mathrm{bar})$. The conversions and selectivities were determined by ${ }^{1} \mathrm{H}$-NMR spectroscopy in $\mathrm{CDCl}_{3}$.

By decreasing the temperature to $60{ }^{\circ} \mathrm{C}$, the reaction slowed down $(6 \mathrm{~h}$ was required for full conversion) meanwhile the selectivity in 2 increased to $96 \%$, with $4 \%$ of hydroxyketone formed from the hydrolysis of $\alpha \mathrm{CC}$ (Table 1, entry 3). When we further decreased the temperature to 40 ${ }^{\circ} \mathrm{C}$, the reaction rate decreased considerably with propargylic alcohol conversion of only $6 \%$ after $1 \mathrm{~h}$ (Table 1, entry 4). Importantly, 2-methyl-3-butyn-2-ol was fully and selectively converted into the desired product $\mathbf{2}$ with no side product when the reaction time was extended to $24 \mathrm{~h}$ (Table 1, entry 5).

In order to improve the selectivity in $\alpha \mathrm{CC} \mathbf{2}$ without excessively compromising the reaction rate, we considered the use of a cocatalyst that was expected to activate the alkyne for the carboxylative addition. Some metal-based catalysts (such as monovalent silver and copper salts) are capable of pi-coordination with the alkyne bond and are therefore expected to be beneficial 
for this reaction. ${ }^{61,62}$ Various salts were tested and results are summarized in Table 2. Adding silver(I) or copper(I) salts favored the reaction. The best catalytic activity was obtained when [TBA] $[\mathrm{OPh}]$ was combined to $\mathrm{CuI}$ or $\mathrm{AgI}$, with an increase in the conversion of $\mathbf{1}$ from $6 \%$ (without cocatalyst, Table 2, entry 1) to $81 \%$ (with CuI, Table 2, entry 7) or $100 \%$ (with AgI, Table 2, entry 3) in $1 \mathrm{~h}$ at 15 bar and $40{ }^{\circ} \mathrm{C}$. Both [TBA][OPh]/CuI and [TBA][OPh]/AgI binary systems drove the reaction with a $100 \%$ selectivity in the targeted product 2 as confirmed by ${ }^{1} \mathrm{H}-$ NMR spectroscopy (Figure S2). The difference in activity for the reactions carried out in the presence of the different silver salts $\left(\mathrm{Ag}_{2} \mathrm{CO}_{3}, \mathrm{AgOAc}\right.$ and $\left.\mathrm{AgI}\right)$ is at this stage difficult to rationalize. However, the different solubility of the silver salts in the reaction medium might be at the origin of this observation. Indeed, when preparing the reaction medium before pressurization with $\mathrm{CO}_{2}$, none of these cocatalysts were fully soluble. However, quantifying their solubility in the reaction medium under pressure was not possible. Verpeort ${ }^{63}$ and Song ${ }^{32}$.

We then screened some solvents using $\mathrm{CuI}$ as cocatalyst and found the reaction to be fastest in acetonitrile and slowest in DMSO (Table 2, entries 7 and 11), with the same selectivity in product $2(100 \%)$.

Table 2. Screening of cocatalyst and solvents for the coupling of $\mathrm{CO}_{2}$ to 2-methyl-3-butyn-2-ol catalyzed by [TBA][OPh]

\begin{tabular}{|c|c|c|c|c|}
\hline Entry & Cocatalyst & Solvent & Conv. of 1 & Selectivity for 2 \\
\hline & & & $(\%)$ & $(\%)$ \\
\hline 1 & I & $\mathrm{ACN}$ & 6 & 100 \\
\hline
\end{tabular}




$\begin{array}{lcccc}\mathbf{2} & \mathrm{Ag}_{2} \mathrm{CO}_{3} & \mathrm{ACN} & 70 & 100 \\ \mathbf{3} & \mathrm{AgI} & \mathrm{ACN} & 100 & 100 \\ \mathbf{4} & \mathrm{AgOAc} & \mathrm{ACN} & 38 & 100 \\ \mathbf{5} & \mathrm{CuCl} & \mathrm{ACN} & 50 & 100 \\ \mathbf{6} & \mathrm{CuBr} & \mathrm{ACN} & 47 & 100 \\ \mathbf{7} & \mathrm{CuI} & \mathrm{ACN} & 81 & 100 \\ \mathbf{8} & \mathrm{CuI} & \mathrm{CDCl} & \\ & & & 63 & 100 \\ \mathbf{9} & \mathrm{CuI} & \mathrm{THF} & 70 & 100 \\ \mathbf{1 0} & \mathrm{CuI} & \mathrm{DMSO} & 58 & 100 \\ \mathbf{1 1} & \mathrm{CuI} & \mathrm{Neat} & 92 & 98\end{array}$

Conditions: 2-methyl-3-butyn-2-ol (2 $\mathrm{mL}, 0.0206 \mathrm{~mol}),[\mathrm{TBA}][\mathrm{OPh}]$ (5 mol\%), cocatalyst (5 mol\%), solvent $(2 \mathrm{~mL}), \mathrm{CO}_{2}(15 \mathrm{bar}), 1 \mathrm{~h}, 40^{\circ} \mathrm{C}$. The conversions and selectivity were determined by ${ }^{1} \mathrm{H}-\mathrm{NMR}$ in $\mathrm{CDCl}_{3}$ (see Figure $\mathrm{Sl}$ for the procedure).

In prelude of our subsequent study on the fabrication of poly(oxo-carbonate)s by the domino reaction, one selected DMSO as the solvent to continue our study. Unlike acetonitrile, its choice was justified by its capability to totally solubilize the bis-propargylic alcohol and provide homogeneous conditions at the initial stage of the reaction. 
To benchmark the activity of the $[\mathrm{TBA}][\mathrm{OPh}], \mathrm{CuI} /[\mathrm{TBA}][\mathrm{OPh}]$ and $\mathrm{AgI} /[\mathrm{TBA}][\mathrm{OPh}]$ catalysts, we studied the kinetics of the reaction using online high-pressure FT-IR spectroscopy at $40{ }^{\circ} \mathrm{C}$ using both $\mathrm{CuI}$ and AgI. Figure 1a shows an overlay of the IR spectra at different times obtained with the $[\mathrm{TBA}][\mathrm{OPh}] / \mathrm{AgI}$ system. We observed a signal at $3300 \mathrm{~cm}^{-1}$ corresponding to the $\mathrm{OH}$ band of the alkynol which decreased gradually overtime and the concomitant formation of the cyclic carbonate and exovinylene group with characteristic vibrations of $\nu \mathrm{C}=\mathrm{O}$ at $1823 \mathrm{~cm}^{-1}$ and $v \mathrm{C}=\mathrm{C}$ at $1680 \mathrm{~cm}^{-1}$. The $\mathrm{CO}_{2}$ band at $2330 \mathrm{~cm}^{-1}$ was observed and remained constant due to the large excess of $\mathrm{CO}_{2}$ under the investigated conditions. A similar profile was obtained with the $[\mathrm{TBA}][\mathrm{OPh}] / \mathrm{CuI}$ system (Figure S3). By following the evolution of the $v \mathrm{C}=\mathrm{O}$ band at $1823 \mathrm{~cm}^{-1}$ (Figure 1b) over time, the yield in exovinylene cyclic carbonate 2 was calculated for the reactions catalyzed by $[\mathrm{TBA}][\mathrm{OPh}],[\mathrm{TBA}][\mathrm{OPh}] / \mathrm{CuI}$ or $[\mathrm{TBA}][\mathrm{OPh}] / \mathrm{AgI}$ systems (Figure 1c, see supporting information for the quantification procedure).
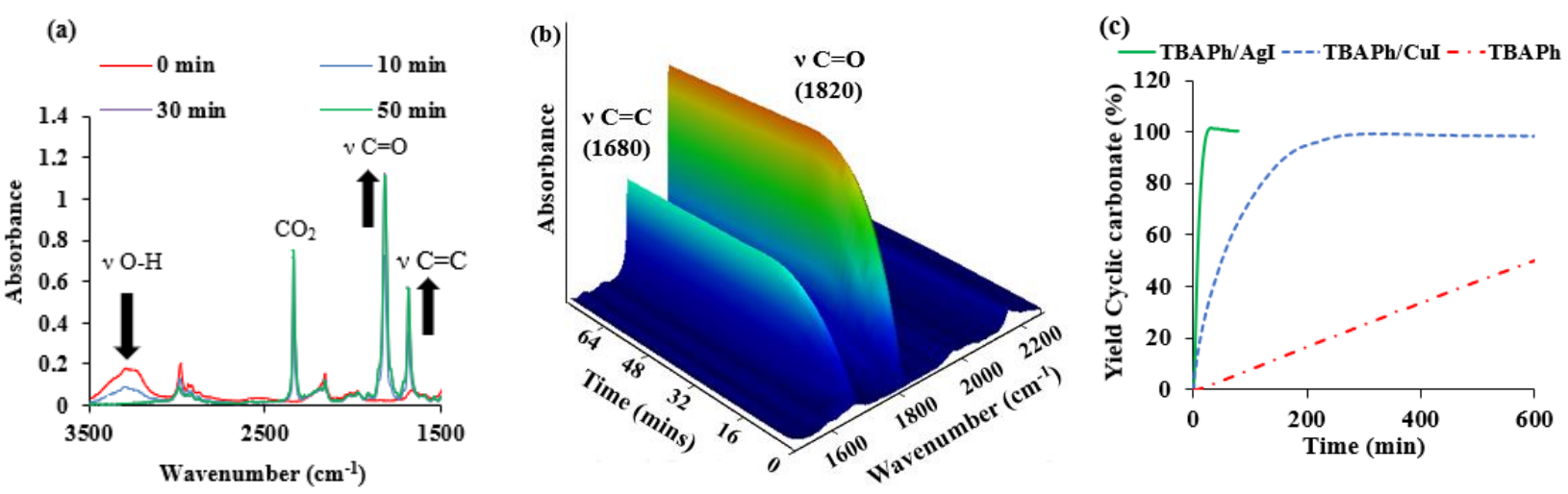

Figure 1. Synthesis of 4,4-dimethyl-5-methylene-1,3-dioxolan-2-one by organocatalyzed coupling of $\mathrm{CO}_{2}$ to 2-methyl-3-butyn-2-ol. (a) FT-IR spectra at different times for the [TBA][OPh]/AgI catalyzed reaction; (b) 3D profile of the 1500 to $2200 \mathrm{~cm}^{-1}$ region obtained by on-line FT-IR spectroscopy for [TBA][OPh]/AgI catalyzed reaction; (c) Yield of cyclic carbonate for the different catalyzed reactions. Conditions: 2-methyl-3-butyn-2-ol (16 mL, 0.165 
$\mathrm{mmol}),[\mathrm{TBA}][\mathrm{OPh}](5 \mathrm{~mol} \%), \mathrm{AgI}$ or $\mathrm{CuI}(5 \mathrm{~mol} \%), \mathrm{T}=40{ }^{\circ} \mathrm{C}, \mathrm{p}_{\mathrm{CO} 2}=15 \mathrm{bar}$, solvent $=\mathrm{DMSO}$ $(\mathrm{V}=16 \mathrm{~mL})$.

The cycloaddition was complete in $180 \mathrm{~min}$ with the $[\mathrm{TBA}][\mathrm{OPh}] / \mathrm{CuI}$ binary system, and in less than 50 min with the $[\mathrm{TBA}][\mathrm{OPh}] / \mathrm{AgI}$ one, no secondary product was detected as already noted during the batch screening tests. By using $[\mathrm{TBA}][\mathrm{OPh}]$ as sole catalyst, the reaction was very slow, requiring $24 \mathrm{~h}$ for completion, but remained selective. This comparative study highlights the synergistic role of the cocatalyst. It must be mentioned that few articles have been published with copper iodide as cocatalyst for this type of reaction. Although high yields were obtained $(70-98 \%)$, moderate to high temperatures $\left(60-120^{\circ} \mathrm{C}\right)$ were most often required ${ }^{33}$. Room temperature operation was recently reported by using $\mathrm{CuI}$ in combination with phosphonium levulinate. However, a high pressure of $\mathrm{CO}_{2}\left(\mathrm{pCO}_{2}=100\right.$ bar $)$ was required and the phosphonium salt was used in large amount $(66 \mathrm{~mol} \%){ }^{61}$ Our system involving $[\mathrm{TBA}][\mathrm{OPh}] / \mathrm{CuI}$ is thus competitive for operating under mild reaction conditions, at a low catalyst loading (5 mol\%).

The mechanism of the carboxylative cyclisation of $\mathbf{1}$ was then investigated by DFT calculations (Figure 2) with the help of the M062X functional (see ESI for details) where the Gibbs free energy of each structure is relative to the sum of the individual Gibbs free energy of the reactants for each pathway, i.e. : propargylic alcohol $+\mathrm{CO}_{2}+[\mathrm{TBA}][\mathrm{OPh}]$ for the reaction catalyzed by the sole $[\mathrm{TBA}][\mathrm{OPh}]$; propargylic alcohol $+\mathrm{CO}_{2}+[\mathrm{TBA}][\mathrm{OPh}]+\mathrm{CuI}(\mathrm{AgI})$ for the reaction catalyzed by [TBA][OPh] / CuI (AgI).

We initially explored the reaction pathway with $[\mathrm{TBA}][\mathrm{OPh}]$ as catalyst only, which is composed of two elementary steps. From the van der Waals complex that exhibits hydrogen bonding between the oxygen atom of the phenolate anion and the hydrogen atom of the hydroxyl 
group of 2-methyl-3-butyn-2-ol, the first step consists of the deprotonation of the propargylic alcohol simultaneously to the nucleophilic attack onto the carbon atom of $\mathrm{CO}_{2}$ with the formation of a carbonate anion intermediate $\left(-11.2 \mathrm{kcal}^{\mathrm{mol}}{ }^{-1}\right)$. The activation barrier of this first step is calculated to be $5.9 \mathrm{kcal}_{\mathrm{mol}}{ }^{-1}$ and, as the transition state associated to it is submerged with respect to the separated reactant limit (fixed at the zero Gibbs free energy), it is supposed to occur very quickly. The second step, which is the rate-determining step with a barrier height of $23.2 \mathrm{kcal}^{\mathrm{mol}}{ }^{-1}$, involves the intramolecular nucleophilic addition from the carbonate anion to the $\mathrm{C} \equiv \mathrm{C}$ bond and the simultaneous protonation of the alkenyl anion by the $\mathrm{PhOH}$ leading to the formation of $\mathbf{2}$ and the regeneration of [TBA][OPh] catalyst.

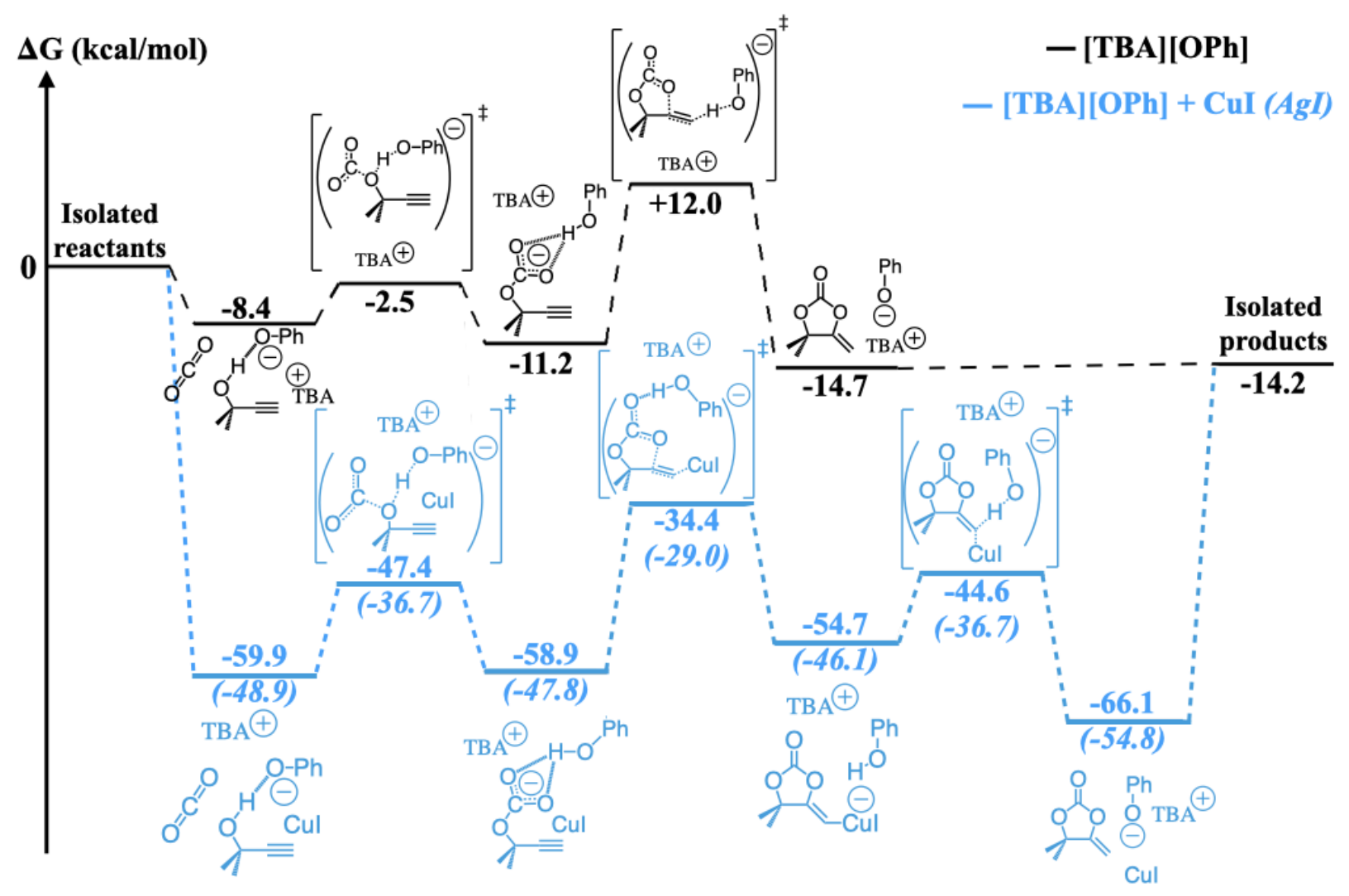

Figure 2. Gibbs free energy profiles for $\alpha$-methylene carbonate formation with [TBA][OPh], $[\mathrm{TBA}][\mathrm{OPh}] / \mathrm{CuI}$ and $[\mathrm{TBA}][\mathrm{OPh}] / \mathrm{AgI}$ as catalytic system 
In the presence of $\mathrm{CuI}$ or $\mathrm{AgI}$ as cocatalyst, the Gibbs free energy profile encountered an important exothermicity (about tens of $\mathrm{kcal}^{\mathrm{mol}}{ }^{-1}$ ), which considerably accelerated the reaction kinetics as observed experimentally. While the first step of the whole reaction is identical to the one with the sole $[\mathrm{TBA}][\mathrm{OPh}]$ catalyst, the 2 remaining steps to form the target product 2 are thus : i) the ring formation from the carbonate anion together with the attack of the $\mathrm{CuI}(\mathrm{AgI})$ on the $\mathrm{C} \equiv \mathrm{C}$ bond with an associated Gibbs free energy barrier of $24.5 \mathrm{kcal} . \mathrm{mol}^{-1}\left(18.8 \mathrm{kcal} . \mathrm{mol}^{-1}\right)$, ii) from the alkenyl metal intermediate a proto-demetallation takes place and the final product is formed by hydrogen proton transfer from $\mathrm{PhOH}$. The Gibbs free energy activation barrier of this last step is calculated to be $10.1 \mathrm{kcal} . \mathrm{mol}^{-1}$ and $9.4 \mathrm{kcal} . \mathrm{mol}^{-1}$ for the cocatalysis with $\mathrm{CuI}$ and AgI, respectively.

To summarize, after the first step of the overall process (addition of $\mathrm{CO}_{2}$ to the propargylic alcohol), the reactants have to overcome the highest energy transition state of $+12 \mathrm{kcal} / \mathrm{mol}$ for the reaction only catalyzed by $[\mathrm{TBA}][\mathrm{OPh}]$. In contrast, in the presence of $\mathrm{CuI}(\mathrm{AgI})$, due to the strong exergonicity a significant part of the reactants might spontaneously react without any stabilization and accelerates the reaction kinetic compare to the case of the reaction only catalyzed by $[\mathrm{TBA}][\mathrm{OPh}]$. On the other hand, in the presence of $\mathrm{CuI}(\mathrm{AgI})$, the remaining part of the species that could be stabilized must undergo activation energies of $18.8 \mathrm{kcal} / \mathrm{mol}$ and 23.2 $\mathrm{kcal} / \mathrm{mol}$ for the reactions co-catalyzed by $\mathrm{AgI}$ and $\mathrm{CuI}$ respectively, indicating that the reaction catalyzed by $[\mathrm{TBA}][\mathrm{OPh}] / \mathrm{AgI}$ is the fastest which is in good agreement with the kinetics studies by online FT-IR experiments. As the binary $[\mathrm{TBA}][\mathrm{OPh}] / \mathrm{AgI}$ systems displayed the highest catalytic activity, it was selected to pursue our objectives of domino reactions and polymerizations. 
Synthesis of oxo-alkylcarbonates. We then evaluated the capacity of the $[\mathrm{TBA}][\mathrm{OPh}]$ and [TBA][OPh]/AgI dual systems to catalyze the alcoholysis of $\alpha \mathrm{CC} \mathbf{2}$ into oxo-alkyl carbonates $\mathbf{3}$ at room temperature $\left(\mathrm{T}=25^{\circ} \mathrm{C}\right)$ in DMSO. The reaction was tested for different alcohols and the results are summarized in Table 3. Importantly, $[\mathrm{TBA}][\mathrm{OPh}](5 \mathrm{~mol} \%)$ displayed sufficient basicity to enable the complete and selective conversion of $\alpha \mathrm{CC} 2$ into the corresponding oxoalkylcarbonate 3 when reacted with 1-butanol for $1 \mathrm{~h}$ at $25{ }^{\circ} \mathrm{C}$, while no reaction was noted without the catalyst (Table 3, entries 1-2). The [TBA][OPh] acted as a hydrogen bond acceptor, thereby activating the alcohol molecule. When $\mathrm{AgI}$ was used as cocatalyst in combination to [TBA][OPh] $\alpha \mathrm{CC} 2$ was selectively converted into the oxo-alkylcarbonate (Table 3, entry 3), similarly to the reaction performed with $[\mathrm{TBA}][\mathrm{OPh}]$ only (Table 3 , entry 2 ). The addition of AgI did not induce any side reaction, at least during the investigated reaction period. We have repeated this experiment for a shorter reaction time (15 min instead of $1 \mathrm{~h})$ and an identical conversion of 2 (100\%) and selectivity for $\mathbf{3}(100 \%)$ were again noted. Although further experiments would be required, it suggests that the silver salt has no noticeable effect on the alcoholysis of the $\alpha$-alkylidene cyclic carbonate, in line with reports of Li and Han.

When using benzyl alcohol, the reaction carried out with $[\mathrm{TBA}][\mathrm{OPh}]$ was also fast, quantitative and selective (Table 3, entry 4). In addition, the selectivity was still excellent, the conversion in $\alpha \mathrm{CC}$ dropped to $68 \%$ when using a less reactive secondary alcohol, 2-propanol, under identical conditions (Table 3, entry 5). No reaction was however noted with the tertiary alcohol, 2-methyl2-butanol (Table 3, entry 6). The lower reactivity of the secondary and tertiary alcohol arose from their steric hindrance that decreased their nucleophilic character. 
Table 3. Alcoholysis of 4,4-dimethyl-5-methylene-1,3-dioxolan-2-one ( $\alpha \mathrm{CC}, 2)$ catalyzed by [TBA][OPh]

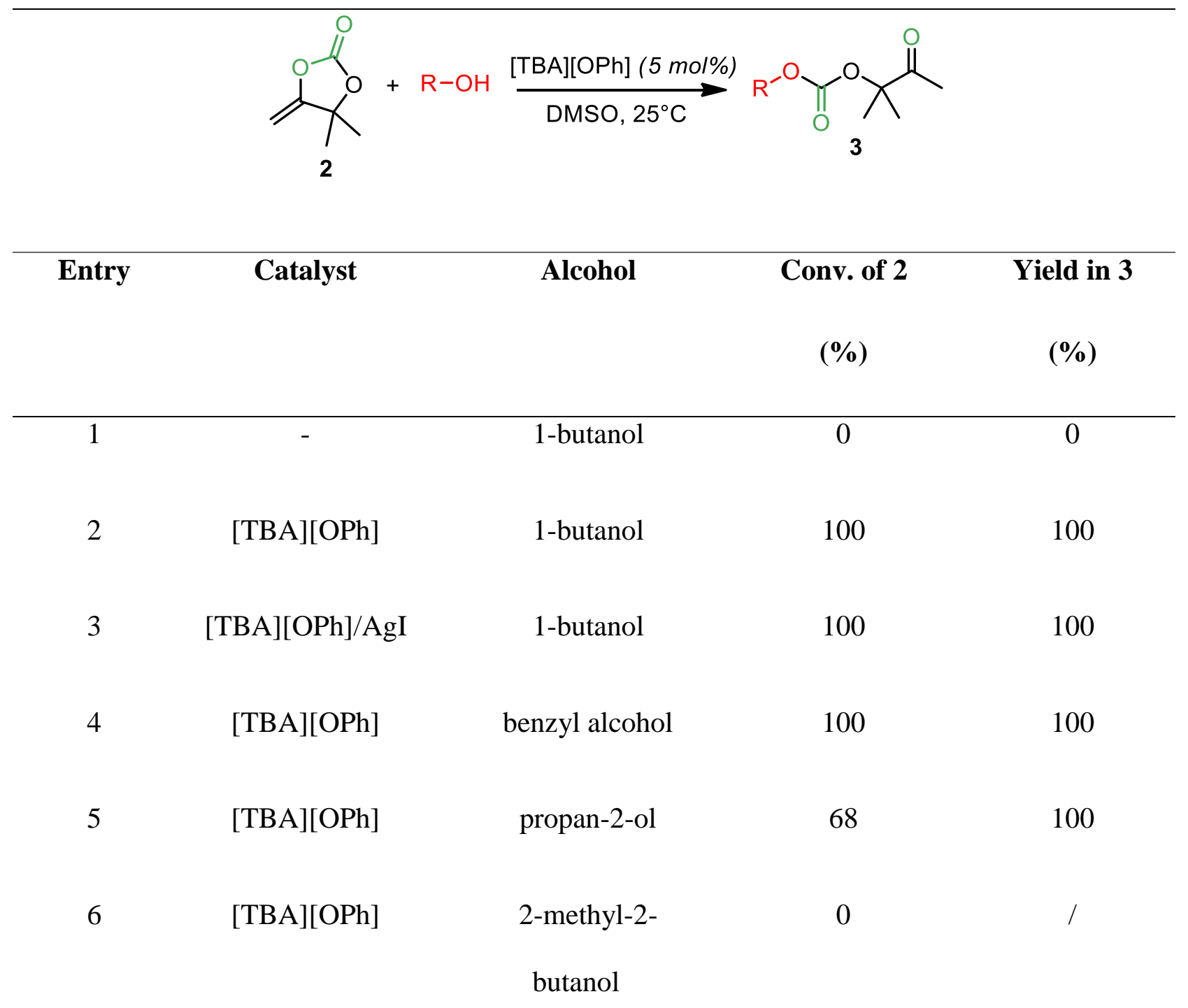

Conditions: $\alpha C C 2(0.5 \mathrm{~g}, 3.904 \mathrm{mmol})$, alcohol (3.904 mmol), [TBA][OPh] (66 mg, $5 \mathrm{~mol} \%)$, cocatalyst (AgI or CuI: $5 \mathrm{~mol} \%), \operatorname{DMSO}(1 \mathrm{ml}), \mathrm{T}=25^{\circ} \mathrm{C}, t=1 \mathrm{~h}$. The conversions and selectivities were determined by ${ }^{1} H-N M R$ in DMSO- $d_{6}$ ( see Figure S4 for the procedure).

Cascade reaction on model compounds. As [TBA][OPh]/AgI was able to catalyze both the selective formation of DMACC by coupling $\mathrm{CO}_{2}$ to 2-methyl-3-butyn-2-ol and its alcoholysis by 
primary and secondary alcohols, we then evaluated its capacity to catalyze the one-pot cascade synthesis of the corresponding oxo-alkylcarbonate 3 from $\mathrm{CO}_{2}$, 2-methyl-3-butynol and 1butanol (Table 4). The reactions were carried out at 15 bar for $6 \mathrm{~h}$, using 5 mol\% of [TBA][OPh] with and without AgI, and different temperatures were screened. Results are presented in Table 4.

Table 4. Cascade synthesis of butyl (2-methyl-3-oxobutan-2-yl) carbonate from 2-methyl-3butyn-2-ol, $\mathrm{CO}_{2}$ and 1-butanol

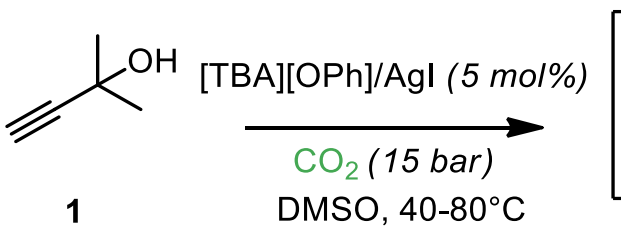

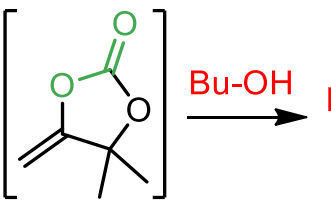

2

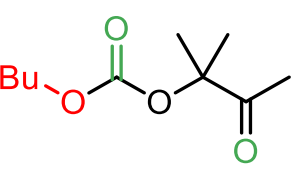

3

\begin{tabular}{lccccc}
\hline Entry & Catalyst & $\mathbf{T}\left({ }^{\circ} \mathbf{C}\right)$ & $\begin{array}{c}\text { Conv. of } \mathbf{1} \\
(\%)\end{array}$ & $\mathbf{2}^{\mathbf{a}}(\mathbf{\%})$ & $\mathbf{3}^{\mathbf{b}}(\mathbf{\%})$ \\
\hline $\mathbf{1}$ & {$[\mathrm{TBA}][\mathrm{OPh}]$} & 40 & 0 & 0 & 0 \\
$\mathbf{2}$ & {$[\mathrm{TBA}][\mathrm{OPh}]$} & 60 & 0 & 0 & 0 \\
$\mathbf{3}$ & {$[\mathrm{TBA}][\mathrm{OPh}]$} & 80 & 15 & 100 & 0 \\
$\mathbf{4}$ & {$[\mathrm{TBA}][\mathrm{OPh}] / \mathrm{AgI}$} & 40 & 100 & 93 & 7 \\
$\mathbf{5}$ & {$[\mathrm{TBA}][\mathrm{OPh}] / \mathrm{AgI}$} & 60 & 100 & 80 & 20 \\
$\mathbf{6}$ & {$[\mathrm{TBA}][\mathrm{OPh}] / \mathrm{AgI}$} & 80 & 100 & 23 & 74
\end{tabular}

Conditions: 2-methyl-3-butyn-2-ol (2 $\mathrm{ml}, 0.02061 \mathrm{~mol})$, 1-butanol $(1.89 \mathrm{ml}, 0.02065 \mathrm{~mol})$, [TBA][OPh] (5 mol\%), AgI (5 mol\%), DMSO (2 ml), CO 2 (15 bar), $6 \mathrm{~h}^{a}$ Selectivity for $2 .{ }^{b}$ Selectivity for 3. The conversions and selectivity were determined by ${ }^{l} H$-NMR in DMSO-d6. (see Figure S5 for the procedure). 
While there is little to no reaction in the absence of $\mathrm{AgI}$ (Table 4, entries 1-3), full conversion of 1 was achieved at $40^{\circ} \mathrm{C}$ after $6 \mathrm{~h}$ of reaction for the [TBA][OPh]/AgI system (Table 4, entry 4). However, the main product was $\alpha \mathrm{CC} 2$ (93\%), with only $7 \%$ of the desired oxo-alkylcarbonate 3. By raising the reaction temperature to 60 or $80^{\circ} \mathrm{C}$, the yield in $\mathbf{3}$ was increased to 20 or $74 \%$, respectively (Table 4, entries 5 and 6).

The influence of the working pressure on the yield and selectivity of the reaction was then evaluated by on-line IR spectroscopy at $60^{\circ} \mathrm{C}$. Unfortunately, because the bands corresponding to the $\mathrm{CC}$ triple bond $\left(890\right.$ and $\left.960 \mathrm{~cm}^{-1}\right)$ and the $\mathrm{OH}$ bond $\left(3260 \mathrm{~cm}^{-1}\right)$ of the propargylic alcohol overlapped with other bands, we could not follow the consumption of the propargylic alcohol over time. However, by analysing a sample of the reaction mixture at the end of each experiment by ${ }^{1} \mathrm{H}-\mathrm{NMR}$ spectroscopy, we could confirm the total conversion of the propargylic alcohol for reactions performed at $\mathrm{p}_{\mathrm{CO} 2}$ of 1,5 or 15 bar. We monitored the formation of $\alpha \mathrm{CC} 2$ and its conversion into the oxo-alkylcarbonate 3 by following the evolution of the carbonyl band of the cyclic carbonate 2 at $1820 \mathrm{~cm}^{-1}$ and of the linear carbonate 3 at $1740 \mathrm{~cm}^{-1}$ (Figure 3a). The yields of each product are plotted $v s$ time in Figure $3 \mathrm{~b}$. At $60{ }^{\circ} \mathrm{C}$ and 15 bar of $\mathrm{CO}_{2}$, the formation of the oxo-alkyl carbonate 3 was observed after about $2.5 \mathrm{~h}$ of reaction and was relatively slow. After $20 \mathrm{~h}$ of reaction, a mixture of product $2(45 \%)$ and $\mathbf{3}(40 \%)$ was collected. By decreasing the $\mathrm{CO}_{2}$ pressure to $5 \mathrm{bar}$, the formation of $\alpha \mathrm{CC} \mathbf{2}$ was faster and its conversion into 3 started after 45 min. After $20 \mathrm{~h}$, the yield in $\mathbf{2}$ was only $3 \%$ while the desired product $\mathbf{3}$ was formed with $87 \%$ yield. Importantly, when the pressure was further reduced to 1 bar, $\alpha \mathrm{CC} 2$ was rapidly formed and was simultaneously converted into $\mathbf{3}$. The domino reaction was complete in less than $10 \mathrm{~h}$ at $1 \mathrm{bar}$ and selective towards the formation of $\mathbf{3}$. These kinetics studies clearly highlight that a low $\mathrm{CO}_{2}$ pressure was required for an efficient domino reaction and for the selective 
production of 3. It was assumed that high $\mathrm{CO}_{2}$ pressure favoured the carbonation of 1-butanol, consequently deactivating it for the alcoholysis of the in-situ formed $\alpha \mathrm{CC} 2$.
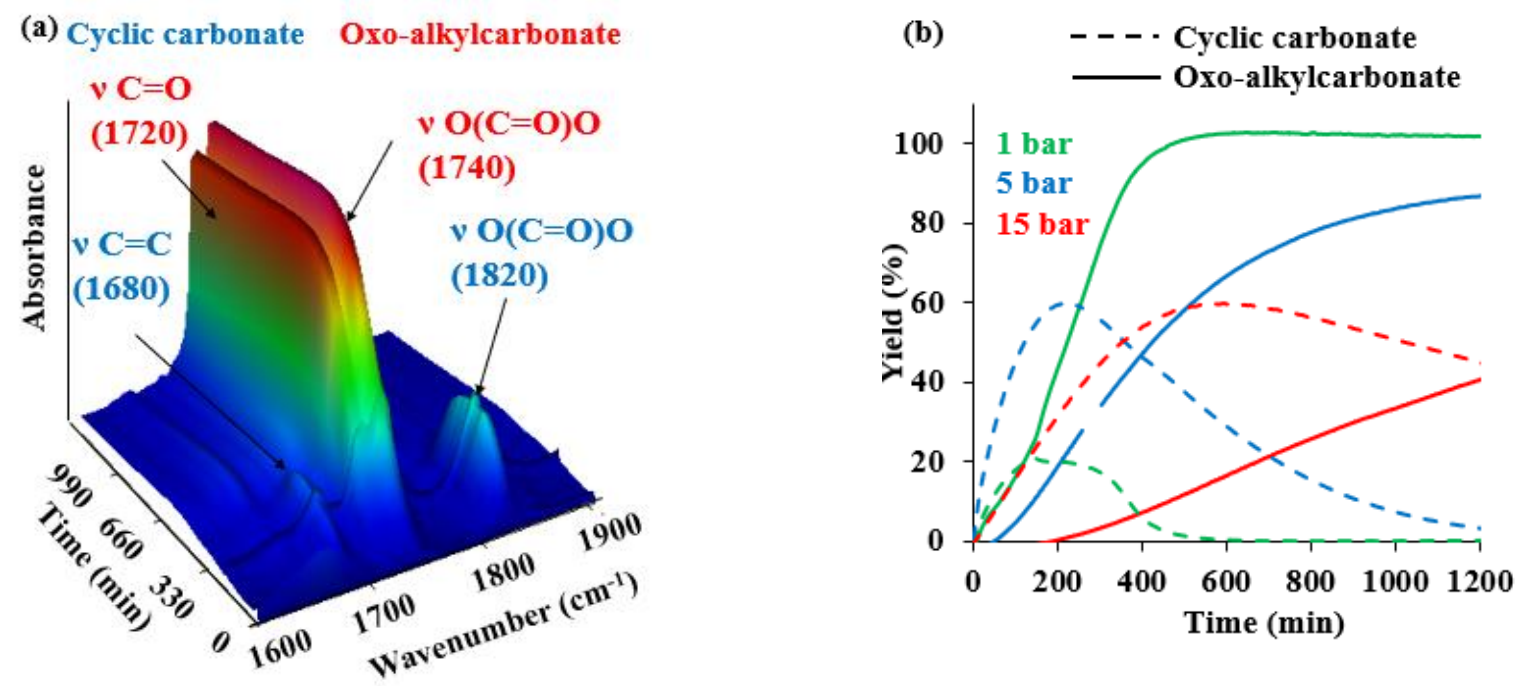

Figure 3. One pot domino synthesis of butyl-(2-methyl-3-oxobutan-2-yl) carbonate from $\mathrm{CO}_{2}, 2$ methyl-3-butyn-2-ol and 1-butanol catalyzed by $[\mathrm{TBA}][\mathrm{OPh}] / \mathrm{AgI}$ at $60{ }^{\circ} \mathrm{C}$. (a) $3 \mathrm{D}$ profile for a reaction conducted at $\mathrm{p}_{\mathrm{CO} 2}$ of 1 bar; (b) influence of $\mathrm{CO}_{2}$ pressure on the formation of cyclic carbonate 2 and oxo-alkylcarbonate 3. Conditions: [TBA][OPh] (5 mol\%), AgI (5 mol\%), 2methyl-3-butyn-2-ol (12 mL), 1-butanol (11.3 mL), DMSO (12 mL)

To give additional clue to this hypothesis, we monitored by online FT-IR spectroscopy the possible formation of a zwitterionic compound from 1-butanol, $\mathrm{CO}_{2}$ and $[\mathrm{TBA}][\mathrm{OPh}]$ in the solvent used for the reaction (DMSO) at a pressure of 15 bar. We indeed observed the rapid growth $(<5 \mathrm{~min})$ of a band at $1660 \mathrm{~cm}^{-1}$ which is typical of the $\mathrm{v} \mathrm{C}=\mathrm{O}$ of a carbonate anion, ${ }^{64}$ thus supporting the in-situ carbonation of 1-butanol favoured at high pressure of 15 bar (Figure S6). 
To higlight the versatility of the $[\mathrm{TBA}][\mathrm{OPh}] / \mathrm{AgI}$ catalytic system for the domino reaction under the optimum conditions $\left(\mathrm{T}=60{ }^{\circ} \mathrm{C}, \mathrm{p}_{\mathrm{CO} 2}=1 \mathrm{bar}, \mathrm{t}=10 \mathrm{~h}\right)$, we enlarged the scope of propargylic alcohols and mono-alcohols to access various oxoalkyl carbonate compounds (Scheme 3).

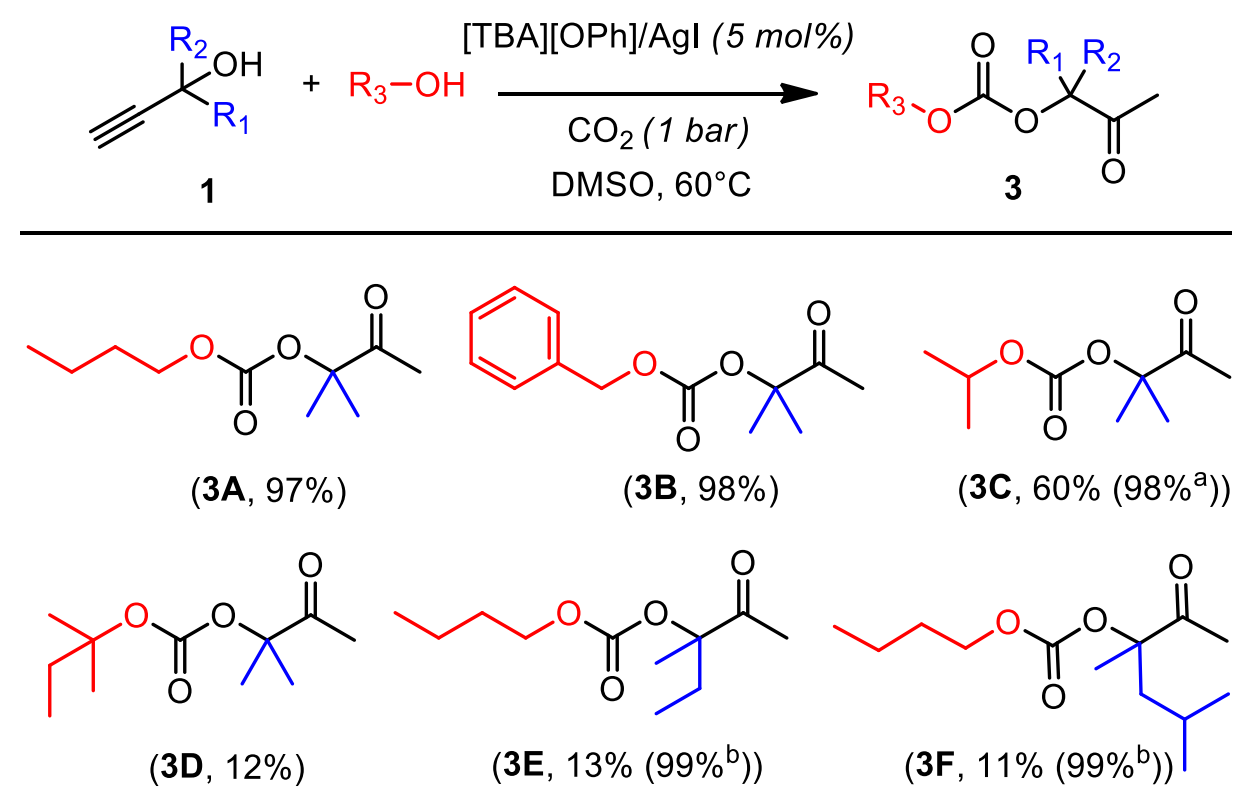

Scheme 3. Product scope for the synthesis of oxo-alkylcarbonates. Conditions: propargylic alcohol (20.61 mmol), aliphatic alcohol (20.61 mmol), [TBA][OPh]/AgI (5 mol\%), DMSO (2 $\mathrm{mL}), \mathrm{p}_{\mathrm{CO} 2}=1 \mathrm{bar}, \mathrm{t}=10 \mathrm{~h}$. Yields were determined by ${ }^{1} \mathrm{H}$ NMR spectroscopy in DMSO- $\mathrm{d}_{6}$ after $24 \mathrm{~h}\left({ }^{\mathrm{a}}\right)$ and $72 \mathrm{~h}\left({ }^{\mathrm{b}}\right)$ under neat conditions. ${ }^{1} \mathrm{H}$ and 13-C NMR are given in Figure S7-S16.

In all cases, all propargylic alcohols were fully consumed. The corresponding oxoalkylcarbonates were formed with a high yield $(\geq 97 \%)$ when primary alcohols such as 1butanol or benzyl alcohol were involved with the less sterically hindered propargylic alcohol, 2methyl-3-butyn-2-ol. When a secondary 2-propanol or tertiary alcohol 2-methyl-2-butanol was employed together with 2-methyl-3-butyn-2-ol, the yields in oxo-alkylcarbonate dropped to $60 \%$ (product 3C) and $12 \%$ (product 3D), respectively. Similarly, when 1-butanol was reacted with 
more sterically hindered propargylic alcohols such as 3-methyl-1-pentyn-3-ol and 3,5-dimethyl1-hexyn-3-ol, very low yields (13\% for product $\mathbf{3 E}$, and $11 \%$ for product $\mathbf{3 F}$ ), respectively, were obtained. The remaining percentage corresponded to the unreacted cyclic carbonate intermediate. Interestingly, by extending the reaction time to $72 \mathrm{~h}$, the selectivity and yield in the target oxo-alkylcarbonates increased to $99 \%$ for both $\mathbf{3 E}$ and $\mathbf{3 F}$.

Synthesis of poly( $\beta$-oxo-carbonate)s by one-pot domino terpolymerization. The reaction conditions were first optimized for the terpolymerization of 4,4'-(ethane-1,2-diyl)bis(4-methyl-5methylene-1,3-dioxolan-2-one) B1, 1,6-hexanediol D1 and $\mathrm{CO}_{2}$ using [TBA][OPh]/AgI as binary catalytic system (Table 5). When carried out in DMSO at 1 bar of $\mathrm{CO}_{2}$, oligomers with a number average molar mass $\left(M_{n}\right)$ of $1,000 \mathrm{~g} / \mathrm{mol}$ were collected after $48 \mathrm{~h}$ at $60{ }^{\circ} \mathrm{C}$ (Table 5 , entry 1). By increasing the $\mathrm{CO}_{2}$ pressure to $15 \mathrm{bar}, M_{n}$ was increased to $1,500 \mathrm{~g} / \mathrm{mol}$, however no significant evolution was observed when the reaction time was extended to $72 \mathrm{~h}$ (Table 5, entries 2 and 3). When the reaction was performed under neat conditions, similar results were obtained. Interestingly the molar mass was almost doubled when using DMF as solvent (Table 5, entries 89). Increasing the reaction temperature to $80{ }^{\circ} \mathrm{C}$ was detrimental to the polymerization with the formation of oligomers of lower $M_{n}$ (Table 5, entries 4 and 5 in DMSO and entry 10 in DMF). Several factors might be at the origin of this observation. First, we demonstrated that increasing the reaction temperature decreased the selectivity in the in-situ formed $\alpha$-alkylidene cyclic carbonate (Table 1), with the consequence that the stoichiometry between $\alpha$-alkylidene cyclic carbonate and alcohol groups is not respected. Second, some thermally induced side reactions (e.g. transcarbonation) might consume reactive groups and thus will provoke a deviation from the perfect stoichiometry, thus lowering the polymer molar mass. 
The SEC elugrams obtained on the crude reaction media (in order to avoid any fractionation of the sample during purification) are presented in Figure S18-21. They show that polymers prepared in DMF were of higher molar mass compared to those produced in DMSO or in the bulk. In the two latter cases, dimers and trimers were clearly observed. Dispersities were rather low for a step-growth polymerization process but are the result of the low molar mass polymers.

Table 5. Screening of parameters for the one pot domino synthesis of poly( $\beta$-oxo-carbonate)s

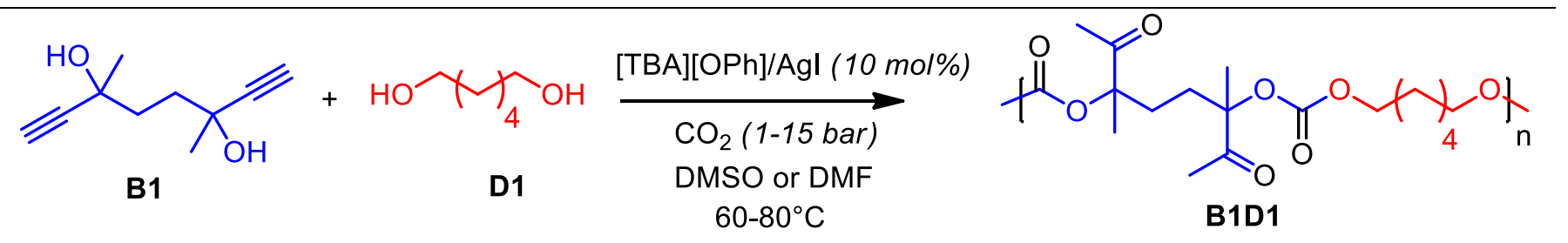

\begin{tabular}{|c|c|c|c|c|c|c|c|c|c|}
\hline Entry & Solvent & $\begin{array}{l}\mathbf{P} \\
\text { (bar) }\end{array}$ & $\begin{array}{l}\text { T } \\
\left({ }^{\circ} \mathbf{C}\right)\end{array}$ & $\begin{array}{l}\text { Time } \\
\text { (h) }\end{array}$ & $\begin{array}{l}{ }^{\mathrm{a}} \text { Conv, of } \\
\mathrm{B}_{1}(\%)\end{array}$ & $\begin{array}{l}{ }^{\mathrm{a} C o n v} \text {, of } \\
\text { D1 (\%) }\end{array}$ & $\begin{array}{l}{ }^{b} M_{n} \\
(g / m o l)\end{array}$ & $\begin{array}{l}{ }^{b} \mathbf{M}_{\mathrm{w}} \\
(\mathrm{g} / \mathrm{mol})\end{array}$ & ${ }^{\mathrm{b}}$ PDI \\
\hline 1 & DMSO & 1 & 60 & 48 & 100 & 20 & $<1000$ & - & - \\
\hline 2 & DMSO & 15 & 60 & 24 & 100 & 61 & 1500 & 1900 & 1.3 \\
\hline 3 & DMSO & 15 & 60 & 72 & 100 & 55 & 1700 & 2300 & 1.3 \\
\hline 4 & DMSO & 15 & 80 & 24 & 100 & 44 & 1500 & 1900 & 1.3 \\
\hline 5 & DMSO & 15 & 80 & 72 & 100 & 50 & 1500 & 1800 & 1.2 \\
\hline 6 & Neat & 15 & 60 & 24 & 100 & 35 & 1400 & 1700 & 1.2 \\
\hline 7 & Neat & 15 & 60 & 72 & 100 & 62 & 2150 & 3100 & 1.4 \\
\hline
\end{tabular}




$\begin{array}{lccccccccr}\mathbf{8} & \text { DMF } & 15 & 60 & 24 & 100 & 73 & 2700 & 4300 & 1.6 \\ \mathbf{9} & \text { DMF } & 15 & 60 & 72 & 100 & 65 & 2600 & 3900 & 1.5 \\ \mathbf{1 0} & \text { DMF } & 15 & 80 & 72 & 100 & 60 & 1600 & 1950 & 1.2\end{array}$

Conditions: bis(propargylic alcohol) B1 $(0.3 \mathrm{~g}, 1.802 \mathrm{mmol}), 1,6$-hexanediol (D1) (0.213 $\mathrm{g}$, $1.802 \mathrm{mmol}),[\mathrm{TBA}][\mathrm{OPh}] / \mathrm{AgI}(10 \mathrm{~mol} \%),[$ bis(propargylic alcohol $)]=1.8 \mathrm{M}$ when a solvent was used.

${ }^{a}$ determined by ${ }^{1} H$ NMR spectroscopy

${ }^{b}$ determined on crude products by GPC using DMF as eluent with PS standard

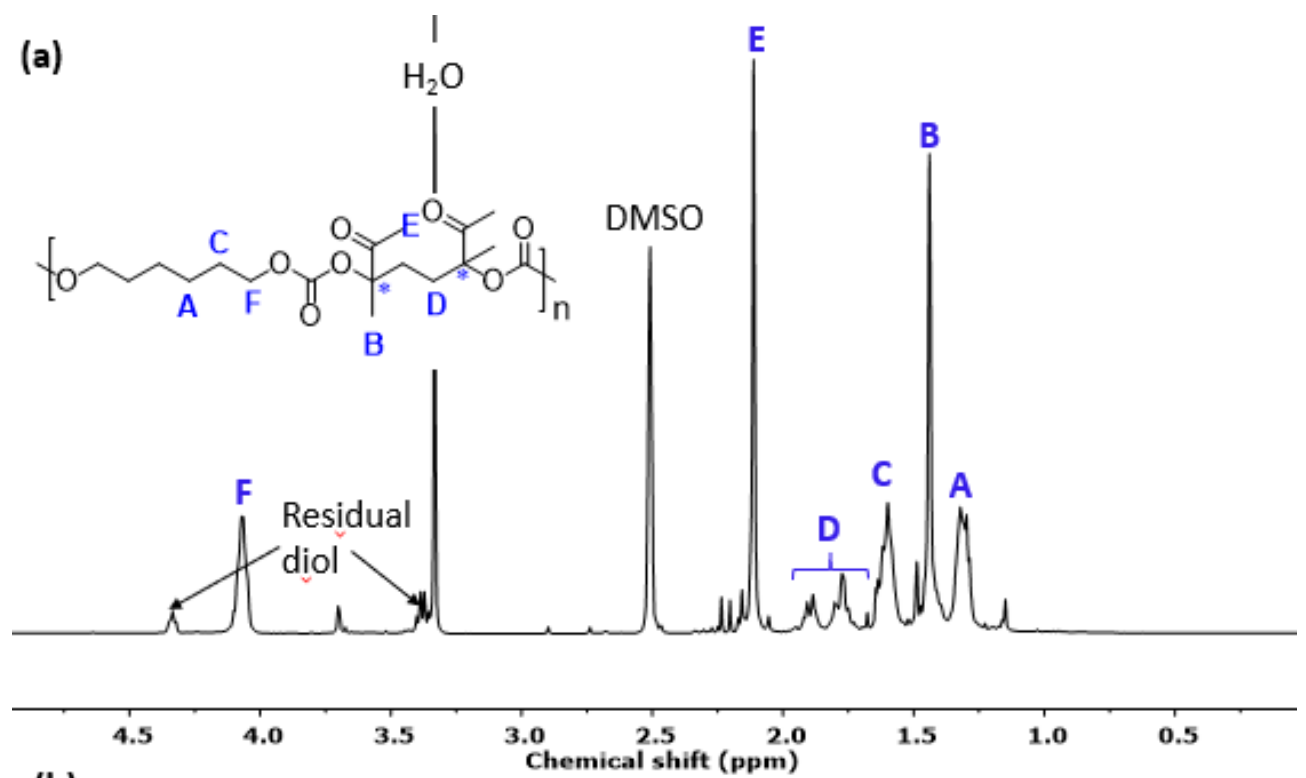

(b)
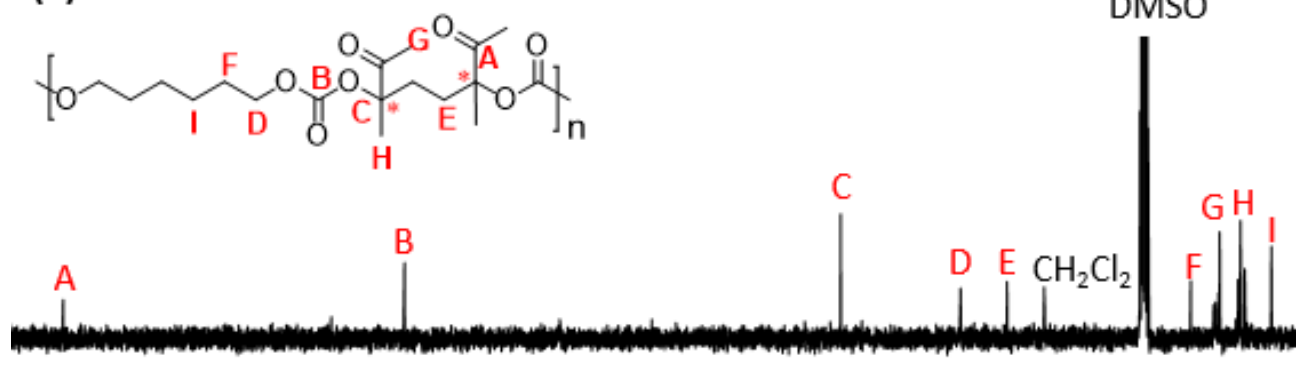

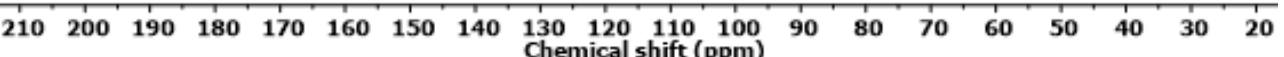


Figure $4(a){ }^{1} H$-NMR and (b) ${ }^{13} C$-NMR spectra in DMSO-d $d_{6}$ of purified poly( $\beta$-oxo-carbonate $)$ $B 1 D 1$

The structure of the poly( $\beta$-oxo-carbonate) was evidenced by ${ }^{1} \mathrm{H}-\mathrm{NMR}$ spectroscopy (Figure 4a) by the presence of a singlet at $\delta=2.11 \mathrm{ppm}$ typical of the methyl group in alpha position of the ketone, at $\delta=1.44 \mathrm{ppm}$ characteristic of the methyl group in alpha of the carbonate and at $\delta=$ $4.06 \mathrm{ppm}$ characteristic of the methylene linked to the carbonate group. The ${ }^{13} \mathrm{C}-\mathrm{NMR}$ (Figure 4b) analysis of the polymer evidenced the resonance of the ketone at $\delta=206 \mathrm{ppm}$ and the carbonate at $\delta=153 \mathrm{ppm}$. All assignments were confirmed by COSY, HSQC and HMBC analysis (Figures S24-26).

The substrate scope was extended by testing other diols (primary D3 and secondary D2, D4) and a cycloaliphatic bis(propargylic alcohol) (B2) (Scheme 4). The corresponding poly( $\beta$-oxocarbonate)s were obtained in all cases, with the structures that were confirmed by ${ }^{1} \mathrm{H}-\mathrm{NMR}$ analyses (Figures S27-S31). Although the molar masses of the polymers cannot be compared (they are obtained based on a polystyrene calibration and the polymers are characterized by different hydrodynamic volumes), the highest $M_{n}$ of $2,700 \mathrm{~g} / \mathrm{mol}\left(M_{w}=4,300 \mathrm{~g} / \mathrm{mol}\right)$ was obtained for B1D1 (Scheme 4). Lower molar masses were collected for polymers prepared from the cycloaliphatic bis(propargylic alcohol) B2. As both B2D1 and B2D2 copolymers were only partly soluble in DMF at room temperature, and because no common organic solvent could totally dissolve them, fractionation of the samples occurred prior their analyses. Their molar masses determined by size exclusion chromatography were probably underestimated. Due to this lack of solubility, the determination of the degree of polymerization by ${ }^{1} \mathrm{H}-\mathrm{NMR}$ spectroscopy was not performed. 

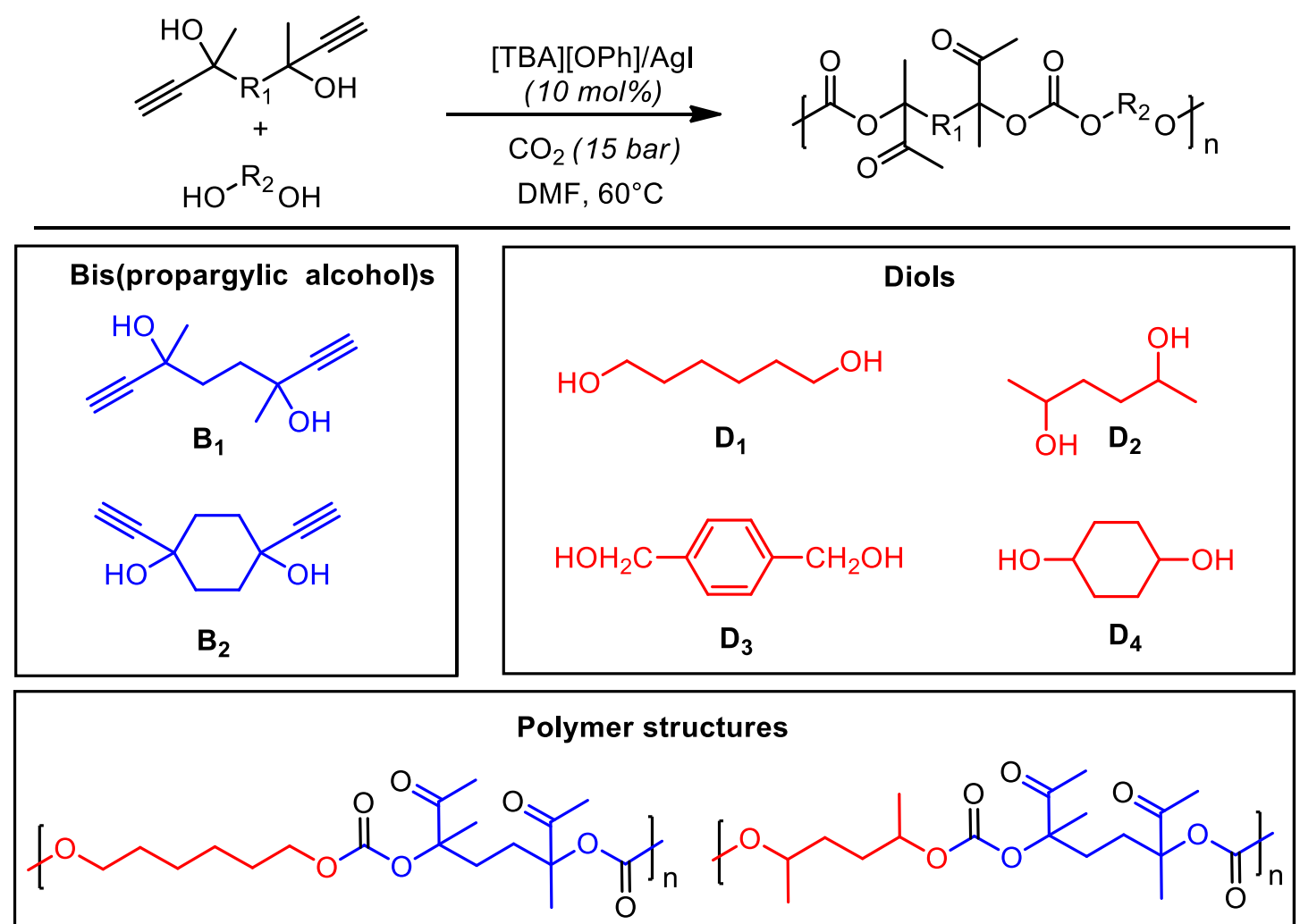

$\mathbf{B}_{1} \mathbf{D}_{1}$ (Mn: $2700 \mathrm{~g} / \mathrm{mol}$, PDI: 1.6)

$\mathbf{B}_{1} \mathbf{D}_{\mathbf{2}}$ (Mn: $\left.1900 \mathrm{~g} / \mathrm{mol}, \mathrm{PDI}: 1.5\right)$<smiles>CC(=O)C(C)(CCC(C)(C(C)=O)C(C)=O)OC(=O)OCc1ccc(COC(=O)OC(C)(C)C)cc1</smiles>

$\mathbf{B}_{1} \mathbf{D}_{\mathbf{3}}(\mathrm{Mn}: 1700 \mathrm{~g} / \mathrm{mol}$, PDI: 1.3 )<smiles>CC(=O)OC(C)(CCC(C)(OC(=O)OC1CCC(OC(C)(C)C)CC1)C(C)=O)C(C)=O</smiles>

$\mathbf{B}_{1} \mathbf{D}_{\mathbf{4}}$ (Mn:1200 g/mol, PDI: 1.3)<smiles>CCOCCCCCCOC(=O)OC1(C(C)=O)CCC(OC(C)=O)(C(C)=O)CC1</smiles>

$\mathbf{B}_{\mathbf{2}} \mathbf{D}_{1}(\mathrm{Mn}: 1200 \mathrm{~g} / \mathrm{mol}, \mathrm{PDI}: 1.2)$<smiles>CC(=O)OC1(C(C)=O)CCC(OC(=O)OC(C)CCC(C)OC(C)(C)C)(C(C)=O)CC1</smiles>

$\mathbf{B}_{\mathbf{2}} \mathbf{D}_{\mathbf{2}}$ (Mn: $1400 \mathrm{~g} / \mathrm{mol}$, PDI: 1.6)

Scheme 4. One-pot domino synthesis of poly( $\beta$-oxo-carbonate)s and reagent scope. $M_{n}$ and PDI determined by SEC in DMF/LiBr with PS standards on crude products. SEC chromatograms of the crude products are provided in Figure S32 and S33. 


\section{CONCLUSIONS.}

In this work, we have disclosed a domino approach to construct oxo-alkylcarbonate scaffolds and polycarbonates from $\mathrm{CO}_{2}$, propargylic alcohols and mono-alcohols under mild operating conditions $\left(\mathrm{pCO}_{2}=1-15\right.$ bar, $\left.\mathrm{T}=40-80{ }^{\circ} \mathrm{C}\right)$. The keystone lied in the design and the utilization of a binary catalyst composed of tetrabutylammonium phenolate that operated in synergy with a $\operatorname{Ag}(\mathrm{I})$ or $\mathrm{Cu}(\mathrm{I})$ salt. Remarkably, this dual catalyst (at 5 mol\% loading) enabled to drive the fast, selective and quantitative formation of exovinylene cyclic carbonates by carboxylative coupling of $\mathrm{CO}_{2}$ to various propargylic alcohols, and it also catalyzed the alcoholysis of the in-situ generated 5-membered cyclic carbonates, providing an efficient platform for the preparation of oxo-alkyl carbonates at high yield. Operando FT-IR spectroscopy correlated to DFT calculations provided kinetic and mechanistic insights that helped us to optimize the one-pot process via a rational comprehension of the reactivity, the efficiency and the selectivity of the binary catalytic system. When this catalytic system was used on mixtures of $\mathrm{CO}_{2}$, bis(propargylic alcohol)s and diols, poly(oxo-carbonate)s with $\mathrm{M}_{\mathrm{w}}$ up to $4,300 \mathrm{~g} / \mathrm{mol}$ were produced by a new domino polymerization process under mild conditions $\left(60^{\circ} \mathrm{C}, 15 \mathrm{bar}\right)$. By varying the nature of the bis(propargylic alcohol) and the diol, various polycarbonates were successfully prepared, enlarging the scope of the process. Ongoing work focuses on the comprehension and the identification of the causes responsible for the moderate molar masses and the solutions to remove their hurdles.

\section{EXPERIMENTAL SECTION}


Materials. Ethynylmagnesium bromide (Acros), silver iodide, silver acetate, silver carbonate, copper chloride, copper bromide, copper iodide, zinc iodide, 2,5-hexandione, 1,4cyclohexandione, 1,6-hexandiol, 2,5-hexandiol, 1,4-butanediol, 1,4-cyclohexandiol (cis/trans mixture), 1-butanol, propan-2-ol, 2-methyl-2-butanol, 2-methyl-3-butyn-2-ol, 3-methyl-1pentyn-3-ol, 3,5-dimethyl-1-hexyn-3-ol were purchased from Aldrich. $\mathrm{CO}_{2}(\mathrm{~N} 27)$ was purchased from Air liquid, dimethyl sulfoxide (DMSO), dimethyl formamide (DMF), acetonitrile (ACN), methanol $(\mathrm{MeOH})$, diethylether. DMSO was dried on a $3 \AA$ molecular sieve conditioned at $100^{\circ} \mathrm{C}$ under vacuum for $24 \mathrm{~h}$. All the other reagents were used as received without any further purification.

Analytical methods.

${ }^{1} \mathrm{H}$ NMR analyses were performed on Bruker Avance $400 \mathrm{MHz}$ spectrometers in DMSO at $25^{\circ} \mathrm{C}$ in the Fourier transform mode. 16 scans for ${ }^{1} \mathrm{H}$ spectra and 512 or 2048 scans for ${ }^{13} \mathrm{C}$ spectra were recorded. Fourier transform infrared spectra were recorded using a Nicolet IS5 spectrometer (Thermo Fisher Scientific) equipped with a transmission or with a diamond attenuated transmission reflectance (ATR) device. Spectra were obtained in transmission or ATR mode as a result of 32 spectra accumulation in the range of $4000-500 \mathrm{~cm}^{-1}$, with a nominal resolution of $4 \mathrm{~cm}^{-1}$.

Number-average molecular weight $\left(\mathrm{M}_{\mathrm{n}}\right)$ and dispersity $(Đ)$ of the different polymers were determined by size exclusion chromatography (SEC) in dimethylformamide (DMF) containing $\operatorname{LiBr}(0.025 \mathrm{M})$ at $55^{\circ} \mathrm{C}$ (flow rate: $\left.1 \mathrm{~mL} / \mathrm{min}\right)$ with a Waters chromatograph equipped with two columns dedicated to the analysis of low molar mass polymers (PSS gram analytical $100 \AA$, separation range 300-60000 Da) and a pre column (100 $)$, a dual $\lambda$ absorbance detector (Waters 
2487) and a refractive index detector (Waters 2414). A previously established PS calibration curve was used.

In-situ IR spectroscopy experiments were conducted using a stainless steel reactor suitable for high-pressure measurements (up to 400 bar) and high temperature (up to $100{ }^{\circ} \mathrm{C}$ ) coupled with a FT-MIR spectrometer from Brucker, equipped with an air-cooled globar source (12V), a $\mathrm{KBr}$ beam splitter, a mechanical rocksolid interferometer, permanently aligned, a diamond ATR fibre probe IN350-T (Ø6 mm) and a liquid nitrogen cooled mercury cadmium telluride (MCT). Single beam spectra recorded in the spectral range $\left(670-3500 \mathrm{~cm}^{-1}\right)$ with a $4 \mathrm{~cm}^{-1}$ resolution were obtained after the Fourier transformation of 32 accumulated interferograms until the end of reaction time.

Screening of the reaction parameters for the carboxylative coupling of $\mathrm{CO}_{2}$ to 3-methyl-2butyn-3-ol. In a clean dry reactor, equipped with a magnetic rod, a manometer and a gas inlet/outlet were introduced 3-methyl-2-butyn-3-ol (2 mL, $20.61 \mathrm{mmol})$, tetrabutylammonium phenolate [TBA][OPh] $(0.3459 \mathrm{~g}, 1.031 \mathrm{mmol}), \mathrm{CuI}(0.1963 \mathrm{~g}, 1.031 \mathrm{mmol})$ and acetonitrile (2 $\mathrm{mL})$. The reactor was closed and placed in a silicon oil bath set heated at the desired temperature. After 30 minutes, $\mathrm{CO}_{2}$ gas was added at a constant pressure. The reaction ran for $1 \mathrm{~h}$ after which the reactor was depressurized and placed in a water bath to cool it down to room temperature. The crude reaction mixture was characterized by ${ }^{1} \mathrm{H}-\mathrm{NMR}$ spectroscopy in $\mathrm{CDCl}_{3}$. For the screening of the reaction parameters ( $\mathrm{T}$, solvent, catalyst), a similar protocol was applied

Monitoring of the carboxylative coupling of $\mathrm{CO}_{2}$ to 3-methyl-2-butyn-3-ol by online FT-IR. In a clean dry reactor of $80 \mathrm{~mL}$ equipped with a manometer, a heating mantle, gas inlet/outlets, a mechanical stirrer and a high pressure FT-IR probe were introduced 3-methyl-2-butyn-3-ol (16 $\mathrm{mL}, \quad 164.9 \mathrm{mmol})$, tetrabutylammonium phenolate [TBA][OPh] $(2.7603 \mathrm{~g}, 8.225 \mathrm{mmol})$, the 
metal salt (AgI, $8.225 \mathrm{mmol})$ and dried DMSO $(16 \mathrm{ml})$. The reactor was closed and heated to the desired temperature after which the FT-IR acquisition was launched. Then $\mathrm{CO}_{2}$ gas was added at constant flow. Spectra were recorded every 2 min. Once the reaction was complete, the reactor was cooled down to room temperature and depressurized. The crude mixture was recovered.

4,4-dimethyl-5-methylene-1,3-dioxolan-2-one (2) ${ }^{1} \mathrm{H}$ NMR (400 MHz, DMSO- $\left.d_{6}\right) \delta($ in ppm) $=$ $4.79(\mathrm{~d}, J=3.8 \mathrm{~Hz}, 1 \mathrm{H}), 4.65(\mathrm{~d}, J=3.8 \mathrm{~Hz}, 1 \mathrm{H}), 1.60(\mathrm{~s}, 6 \mathrm{H})$.

${ }^{13} \mathrm{C}$ NMR $\left(100.6 \mathrm{MHz}\right.$, DMSO- $\left.d_{6}\right) \delta($ in ppm $)=158.67,151.28,85.92,85.56,27.37$.

General procedure for the synthesis of butyl-(2-methyl-3-oxobutan-2-yl) carbonate by alcoholysis of $\alpha C \boldsymbol{C} 2$. In a clean dry glass reaction tube, equipped with a magnetic rod and a three-way stopcock were introduced; 4,4-dimethyl-5-methylene-1,3-dioxolan-2-one (0.5 g, 3.904 $\mathrm{mmol})$, butanol $(0.357 \mathrm{ml}, 3.904 \mathrm{mmol})$, tetrabutylammonium phenolate [TBA][OPh] $(0.0664 \mathrm{~g}$, $0.1952 \mathrm{mmol})$ and DMSO $(1 \mathrm{ml})$. The reaction tube was placed in a silicon oil bath set at $25^{\circ} \mathrm{C}$. The reaction mixture was sampled after $15 \mathrm{~min}, 1 \mathrm{~h}, 2 \mathrm{~h}$ and $24 \mathrm{~h}$, and characterized by ${ }^{1} \mathrm{H}$ NMR spectroscopy in DMSO- $\mathrm{d}_{6}$.

General procedure for the domino synthesis of butyl-(2-methyl-3-oxobutan-2-yl) carbonate from 2-methyl-3-butyn-2-ol, $\mathrm{CO}_{2}$ and alcohol. In a stainless-steel reactor of $12 \mathrm{~mL}$ equipped with a magnetic bar, a manometer and a gas inlet/outlet were introduced 3-methyl-2-butyn-3-ol (2 mL, $20.61 \mathrm{mmol})$, tetrabutylammonium phenolate [TBA][OPh] (0.3459 g, $1.031 \mathrm{mmol})$, AgI $(0.2419 \mathrm{~g}, 1.031 \mathrm{mmol})$ and 1-butanol $(1.88 \mathrm{~mL}, 20.55 \mathrm{mmol})$. The reactor was closed and placed in a silicon oil bath set at $60^{\circ} \mathrm{C}$. After $30 \mathrm{~min}, \mathrm{CO}_{2}$ was added at a constant pressure of 15 bar. The reaction ran for $6 \mathrm{~h}$ after which the reactor was slowly depressurized and placed in a water bath to cool it down to room temperature. The crude reaction mixture was characterized by 
${ }^{1} \mathrm{H}-\mathrm{NMR}$ spectroscopy in DMSO- $\mathrm{d}_{6}$. Then the catalyst was removed by silica gel chromatography with $\mathrm{CH}_{2} \mathrm{Cl}_{2}$, and the product dried under vacuum at room temperature for $24 \mathrm{~h}$.

Monitoring of the synthesis of butyl-(2-methyl-3-oxobutan-2-yl) carbonate by on-line FT-IR.

In a clean dry reactor of $80 \mathrm{~mL}$ equipped with a manometer, a heating mantle, gas inlet/outlets, a mechanical stirrer and a high pressure FT-IR probe were introduced 3-methyl-2-butyn-3-ol (12 mL, $123.6 \mathrm{mmol}), 1$-butanol (11.3 mL, $123.6 \mathrm{mmol})$, [TBA][OPh] (2.0749 g, $6.182 \mathrm{mmol}), \mathrm{AgI}$ $(6.182 \mathrm{mmol})$ and dried DMSO $(12 \mathrm{~mL})$. The reactor was closed and heated to the desired temperature after which the FT-IR acquisition was launched and recorded every $5 \mathrm{~min}$. Then $\mathrm{CO}_{2}$ gas was added at constant flow. Once the reaction was complete, the reactor was cooled down to room temperature and depressurized. The crude mixture was recovered and characterized by ${ }^{1} \mathrm{H}-\mathrm{NMR}$ spectroscopy in DMSO- $\mathrm{d}_{6}$.

Butyl-(2-methyl-3-oxobutan-2-yl) carbonate (product 3A)

${ }^{1} \mathrm{H}$ NMR $\left(400 \mathrm{MHz}\right.$, DMSO- $\left.d_{6}\right) \delta($ in ppm $)=4.08(\mathrm{t}, J=6.6 \mathrm{~Hz}, 2 \mathrm{H}), 2.12(\mathrm{~s}, 3 \mathrm{H}), 1.62-1.52$ (m, 2H), $1.43(\mathrm{~s}, 6 \mathrm{H}), 1.42-1.28(\mathrm{~m}, 2 \mathrm{H}), 0.89(\mathrm{t}, J=7.4 \mathrm{~Hz}, 3 \mathrm{H})$.

${ }^{13} \mathrm{C}$ NMR $\left(100.6 \mathrm{MHz}\right.$, DMSO- $\left.d_{6}\right) \delta($ in $\mathrm{ppm})=206.50,153.92,85.11,67.90,40.90,30.55$ $24.13,23.33,18.83,13.92$.

These NMR data are in agreement with those reported in the scientific literature.

Benzyl-(2-methyl-3-oxobutan-2-yl) carbonate (Product 3B)

${ }^{1} \mathrm{H}$ NMR $\left(400 \mathrm{MHz}\right.$, DMSO- $\left.d_{6}\right) \delta($ in ppm $)=7.39(\mathrm{~s}, 4 \mathrm{H}), 7.45-7.32(\mathrm{~m}, 1 \mathrm{H}), 5.15(\mathrm{~s}, 2 \mathrm{H}), 2.10$ (s, 3H), $1.45(\mathrm{~s}, 6 \mathrm{H})$. 
${ }^{13} \mathrm{C}$ NMR $\left(100.6 \mathrm{MHz}, \mathrm{DMSO}-d_{6}\right) \delta 206.43(\mathrm{C}=\mathrm{O}), 153.77(\mathrm{OC}=\mathrm{OO}), 135.78,128.97,128.89$, $128.60,85.50,69.55,24.18,23.34$.

These NMR data are in agreement with those reported in the scientific literature.

Isopropyl-(2-methyl-3-oxobutan-2-yl) carbonate (Product 3C)

${ }^{1} \mathrm{H}$ NMR $\left(400 \mathrm{MHz}\right.$, DMSO- $\left.d_{6}\right) \delta($ in ppm) $=4.74(\mathrm{p}, J=6.2 \mathrm{~Hz}, 1 \mathrm{H}), 2.11(\mathrm{~s}, 3 \mathrm{H}), 1.43(\mathrm{~s}, 6 \mathrm{H})$, $1.23(\mathrm{~d}, J=6.2 \mathrm{~Hz}, 6 \mathrm{H})$.

These NMR data are in agreement with those reported in the scientific literature.

${ }^{13} \mathrm{C}$ NMR $\left(100.6 \mathrm{MHz}\right.$, DMSO- $\left.d_{6}\right) \delta($ in ppm $)=206.57,153.32,84.95,72.30,24.08,23.34,21.86$

2-methyl-3-oxobutan-2-yl tert-pentyl carbonate (Product 3D)

${ }^{1} \mathrm{H}$ NMR $\left(400 \mathrm{MHz}\right.$, DMSO- $\left.d_{6}\right) \delta($ in ppm $)=2.10(\mathrm{~s}, 3 \mathrm{H}), 1.75(\mathrm{q}, J=7.5 \mathrm{~Hz}, 2 \mathrm{H}), 1.40(\mathrm{~s}, 6 \mathrm{H})$, 1.37 (s, 6H), 0.84 (dt, $J=9.3,7.5 \mathrm{~Hz}, 3 \mathrm{H})$.

${ }^{13} \mathrm{C}$ NMR $\left(100.6 \mathrm{MHz}\right.$, DMSO- $\left.d_{6}\right) \delta($ in ppm $)=206.24,152.19,84.91,84.35,36.29,25.38$, $23.71,23.16,8.21$

Butyl-(3-methyl-2-oxopentan-3-yl) carbonate (Product 3E)

${ }^{1} \mathrm{H}$ NMR $\left(400 \mathrm{MHz}\right.$, DMSO- $\left.d_{6}\right) \delta($ in ppm $)=4.08(\mathrm{tt}, J=6.9,3.4 \mathrm{~Hz}, 2 \mathrm{H}), 2.10(\mathrm{~s}, 3 \mathrm{H}), 1.87(\mathrm{dq}$, $J=15.0,7.5 \mathrm{~Hz}, 1 \mathrm{H}), 1.72(\mathrm{dq}, J=14.7,7.5 \mathrm{~Hz}, 1 \mathrm{H}), 1.57(\mathrm{~h}, J=6.3,5.8 \mathrm{~Hz}, 2 \mathrm{H}), 1.43(\mathrm{~s}, 3 \mathrm{H})$, $1.34(\mathrm{~h}, J=7.3 \mathrm{~Hz}, 2 \mathrm{H}), 0.90$ (t, $J=7.4 \mathrm{~Hz}, 3 \mathrm{H}), 0.81(\mathrm{t}, J=7.5 \mathrm{~Hz}, 3 \mathrm{H})$.

${ }^{13} \mathrm{C}$ NMR $\left(100.6 \mathrm{MHz}, \mathrm{DMSO}-d_{6}\right) \delta($ in ppm $)=206.43(\mathrm{C}=\mathrm{O}), 153.77(\mathrm{OC}=\mathrm{OO}), 87.94,68.46$, $30.86,28.89,24.32,19.68,18.70,14.06,7.45$ 
Butyl (3,5-dimethyl-2-oxohexan-3-yl) carbonate (Product 3F)

${ }^{1} \mathrm{H}$ NMR $\left(400 \mathrm{MHz}, \mathrm{DMSO}-d_{6}\right) \delta($ in ppm $)=4.08(\mathrm{td}, J=6.6,3.1 \mathrm{~Hz}, 2 \mathrm{H}), 2.11(\mathrm{~s}, 3 \mathrm{H}), 1.71$ $(\mathrm{dd}, J=13.2,6.9 \mathrm{~Hz}, 2 \mathrm{H}), 1.58(\mathrm{dd}, J=8.3,6.3 \mathrm{~Hz}, 2 \mathrm{H}), 1.48(\mathrm{~s}, 3 \mathrm{H}), 1.33(\mathrm{q}, J=7.5 \mathrm{~Hz}, 3 \mathrm{H})$, $0.90(\mathrm{dt}, J=8.0,4.4 \mathrm{~Hz}, 9 \mathrm{H})$.

${ }^{13} \mathrm{C}$ NMR $\left(100.6 \mathrm{MHz}\right.$, DMSO- $\left.d_{6}\right) \delta($ in ppm $)=206.24(\mathrm{C}=\mathrm{O}), 153.77(\mathrm{OC}=\mathrm{OO}), 87.58,67.83$, $44.07,30.54,24.60,23.85,23.78,20.79,18.80,13.92$

General procedure for the domino synthesis of poly( $\beta$-oxocarbonate)s by terpolymerization. In a stainless-steel reactor of $12 \mathrm{~mL}$ equipped with a magnetic bar, a manometer and a gas inlet/outlet were introduced 4,4'-(ethane-1,2-diyl)bis(4-methyl-5-methylene-1,3-dioxolan-2-one) B1 $(0.3 \mathrm{~g}, 1.802 \mathrm{mmol})$ prepared following Gennen's protocol ${ }^{40}, 1,6$-hexandiol D1 $(0.2130 \mathrm{~g}$, $1.802 \mathrm{mmol})$, tetrabutylammonium phenolate $(60.5 \mathrm{mg}, 0.1802 \mathrm{mmol}), \mathrm{AgI}(42.3 \mathrm{mg}, 0.1802$ mmol) and DMF (1mL). The reactor was closed and placed in a silicon oil bath set at $60{ }^{\circ} \mathrm{C}$. After 30 min, $\mathrm{CO}_{2}$ was added at a constant pressure of 15 bar. The reaction ran for $24 \mathrm{~h}$, after which the reactor was depressurized and placed in a water bath to cool it down to room temperature. A sample of the reaction mixture was characterized by ${ }^{1} \mathrm{H}$-and ${ }^{13} \mathrm{C}-\mathrm{NMR}$ in DMSO$\mathrm{d}_{6}$ to determine the conversion and by SEC in order to evaluate the molecular parameters of the polymer. Then the catalyst was removed by silica gel chromatography with $\mathrm{CH}_{2} \mathrm{Cl}_{2}$. The solvent was evaporated, and the sample washed 4 times with a mixture of water and $\mathrm{CH}_{2} \mathrm{Cl}_{2}$ (5:1) to eliminate DMF. The organic phase was collected, and $\mathrm{CH}_{2} \mathrm{Cl}_{2}$ removed under vacuum at room temperature.

\section{ASSOCIATED CONTENT}


Supporting Information is available free of charge via the Internet at http://pubs.acs.org. It describes the methodology to calculate the reactant conversion by ${ }^{1} \mathrm{H}$ NMR for the model alcoholysis of $\alpha \mathrm{CC}$, the monitoring of the carboxylative cyclization of 2-methyl-3-butyn-2-ol and the carbonation of primary alcohol via operando FT-IR, the structural NMR characterizations of the reactant, crude and isolated oxo-alkylcarbonates and oligo(oxocarbonate)s and finally the SEC elugrams of the oligomers synthesized by the domino process and details for the DFT calculations.

\section{AUTHOR INFORMATION}

\section{Corresponding Author}

* christophe.detrembleur@uliege.be

Author Contributions. The manuscript was written through contributions of all authors. / All authors have given approval to the final version of the manuscript.

Funding Sources. This research was partially funded by the Fonds National de la Recherche Scientifique (FNRS) and the Fonds Wetenschappelijk Onderzoek - Vlaanderen (FWO) in the frame of the EOS project $n^{\circ}$ O019618F (ID EOS: 30902231) and by FNRS in the frame of the FRIA project of C. Ngassam.

Notes. Any additional relevant notes should be placed here.

\section{ACKNOWLEDGMENT}

The authors of Liège thank the Fonds National de la Recherche Scientifique (FNRS) and the Fonds Wetenschappelijk Onderzoek - Vlaanderen (FWO) for funding the EOS project $\mathrm{n}^{\circ} \mathrm{O} 019618 \mathrm{~F}$ (ID EOS: 30902231) and the FNRS in the frame of the FRIA project of C. 
Ngassam. C. Detrembleur is FNRS Research Director. Computer time was provided by the Pôle Modélisation HPC facilities of the Institut des Sciences Moléculaires UMR 5255 CNRS Université de Bordeaux, co-funded by the Nouvelle Aquitaine region.

\section{REFERENCES}

(1) Alves, M.; Grignard, B.; Gennen, S.; Mereau, R.; Detrembleur, C.; Jerome, C.; Tassaing, T. Organocatalytic Promoted Coupling of Carbon Dioxide with Epoxides: A Rational Investigation of the Cocatalytic Activity of Various Hydrogen Bond Donors. Catal. Sci. Technol. 2015, 5 (9), 4636-4643. https://doi.org/10.1039/c5cy00891c.

(2) Alves, M.; Grignard, B.; Mereau, R.; Jerome, C.; Tassaing, T.; Detrembleur, C. Organocatalyzed Coupling of Carbon Dioxide with Epoxides for the Synthesis of Cyclic Carbonates: Catalyst Design and Mechanistic Studies. Catal. Sci. Technol. 2017, 7 (13), 2651-2684. https://doi.org/10.1039/c7cy00438a.

(3) Fiorani, G.; Guo, W.; Kleij, A. W. Sustainable Conversion of Carbon Dioxide: The Advent of Organocatalysis. Green Chem. 2015, 17 (3), 1375-1389. https://doi.org/10.1039/c4gc01959h.

(4) Büttner, H.; Longwitz, L.; Steinbauer, J.; Wulf, C.; Werner, T. Recent Developments in the Synthesis of Cyclic Carbonates from Epoxides and CO2. Top. Curr. Chem. 2017, 375 (3), 1-56. https://doi.org/10.1007/s41061-017-0136-5.

(5) Kleij, A. W. Green Catalytic Synthesis of Heterocyclic Structures Using Carbon Dioxide and Related Motifs. In Green Synthetic Approaches for Biologically Relevant Heterocycles; Elsevier Inc., 2015; pp 141-162. https://doi.org/10.1016/B978-0-12- 
800070-0.00006-2.

(6) Zhang, Q.; Yuan, H. Y.; Fukaya, N.; Yasuda, H.; Choi, J. C. A Simple Zinc Catalyst for Carbamate Synthesis Directly from CO2. ChemSusChem 2017, 10 (7), 1501-1508. https://doi.org/10.1002/cssc.201601878.

(7) Zhang, Q.; Yuan, H. Y.; Fukaya, N.; Choi, J. C. Alkali Metal Salt as Catalyst for Direct Synthesis of Carbamate from Carbon Dioxide. ACS Sustain. Chem. Eng. 2018, 6 (5), 6675-6681. https://doi.org/10.1021/acssuschemeng.8b00449.

(8) Arshadi, S.; Banaei, A.; Ebrahimiasl, S.; Monfared, A.; Vessally, E. Solvent-Free Incorporation of $\mathrm{CO} 2$ into 2-Oxazolidinones: A Review. RSC Adv. 2019, 9 (34), 1946519482. https://doi.org/10.1039/c9ra00551j.

(9) Zhang, Q.; Yuan, H. Y.; Fukaya, N.; Yasuda, H.; Choi, J. C. Direct Synthesis of Carbamate from CO2 Using a Task-Specific Ionic Liquid Catalyst. Green Chem. 2017, 19 (23), 5614-5624. https://doi.org/10.1039/c7gc02666h.

(10) Sengoden, M.; North, M.; Whitwood, A. C. Synthesis of Oxazolidinones by Using Carbon Dioxide as a C1 Building Block and an Aluminium-Based Catalyst. ChemSusChem 2019, 12 (14), 3296-3303. https://doi.org/10.1002/cssc.201901171.

(11) Pulla, S.; Felton, C. M.; Ramidi, P.; Gartia, Y.; Ali, N.; Nasini, U. B.; Ghosh, A. Advancements in Oxazolidinone Synthesis Utilizing Carbon Dioxide as a C1 Source. $J$. CO2 Util. 2013, 2, 49-57. https://doi.org/10.1016/j.jcou.2013.07.005.

(12) Song, J.; Liu, Q.; Liu, H.; Jiang, X. Recent Advances in Palladium-Catalyzed 
Carboxylation with CO2. European J. Org. Chem. 2018, 2018 (6), 696-713. https://doi.org/10.1002/ejoc.201701436.

(13) Luo, J.; Larrosa, I. C-H Carboxylation of Aromatic Compounds through CO2 Fixation. ChemSusChem 2017, 10 (17), 3317-3332. https://doi.org/10.1002/cssc.201701058.

(14) Yu, B.; Diao, Z. F.; Guo, C. X.; He, L. N. Carboxylation of Olefins/Alkynes with CO2 to Industrially Relevant Acrylic Acid Derivatives. J. CO2 Util. 2013, 1, 60-68. https://doi.org/10.1016/j.jcou.2013.01.001.

(15) Grignard, B.; Gennen, S.; Jérôme, C.; Kleij, A. W.; Detrembleur, C. Advances in the Use of $\mathrm{CO} 2$ as a Renewable Feedstock for the Synthesis of Polymers. Chem. Soc. Rev. 2019, 48 (16), 4466-4514. https://doi.org/10.1039/c9cs00047j.

(16) Martín, C.; Kleij, A. W. Terpolymers Derived from Limonene Oxide and Carbon Dioxide: Access to Cross-Linked Polycarbonates with Improved Thermal Properties. $\begin{array}{lllll}\text { Macromolecules } & \mathbf{2 0 1 6}, & 49 & \text { (17), }\end{array}$ https://doi.org/10.1021/acs.macromol.6b01449.

(17) Yadav, N.; Seidi, F.; Crespy, D.; D’Elia, V. Polymers Based on Cyclic Carbonates as Trait d'Union Between Polymer Chemistry and Sustainable CO2 Utilization. ChemSusChem 2019, 12 (4), 724-754. https://doi.org/10.1002/cssc.201802770.

(18) Poland, S. J.; Darensbourg, D. J. A Quest for Polycarbonates Provided: Via Sustainable Epoxide/CO2 Copolymerization Processes. Green Chem. 2017, 19 (21), 4990-5011. https://doi.org/10.1039/c7gc02560b. 
(19) Zhu, Y.; Romain, C.; Williams, C. K. Sustainable Polymers from Renewable Resources. Nature 2016, 540 (7633), 354-362. https://doi.org/10.1038/nature21001.

(20) Kamphuis, A. J.; Picchioni, F.; Pescarmona, P. P. CO2-Fixation into Cyclic and Polymeric Carbonates: Principles and Applications. Green Chem. 2019, 21 (3), 406-448. https://doi.org/10.1039/c8gc03086c.

(21) Grignard, B.; Thomassin, J.; Gennen, S.; Poussard, L.; Bonnaud, L.; Raquez, J.; Dubois, P.; Tran, M.; Park, C. B.; Jerome, C.; et al. CO2-Blown Microcellular Non-Isocyanate Polyurethane (NIPU) Foams: From Bio- and CO2-Sourced Monomers to Potentially Thermal Insulating Materials. Green Chem. 2016, 18 (7), 2206-2215. https://doi.org/10.1039/c5gc02723c.

(22) Carrø, C.; Ecochard, Y.; Caillol, S.; Avørous, L. From the Synthesis of Biobased Cyclic Carbonate to Polyhydroxyurethanes: A Promising Route towards Renewable NonIsocyanate Polyurethanes. ChemSusChem 2019, 12, 1-22. https://doi.org/10.1002/cssc.201900737.

(23) Poussard, L.; Mariage, J.; Grignard, B.; Detrembleur, C.; Jéroîme, C.; Calberg, C.; Heinrichs, B.; De Winter, J.; Gerbaux, P.; Raquez, J. M.; Dubois, P. Non-Isocyanate Polyurethanes from Carbonated Soybean Oil Using Monomeric or Oligomeric Diamines to Achieve Thermosets or Thermoplastics. Macromolecules 2016, 49 (6), 2162-2171. https://doi.org/10.1007/s10526-016-9781-9.

(24) Gennen, S.; Grignard, B.; Thomassin, J. M.; Gilbert, B.; Vertruyen, B.; Jerome, C.; Detrembleur, C. Polyhydroxyurethane Hydrogels: Synthesis and Characterizations. Eur. 
Polym. J. 2016, 84, 849-862. https://doi.org/10.1016/j.eurpolymj.2016.07.013.

(25) Rabnawaz, M.; Wyman, I.; Auras, R.; Cheng, S. A Roadmap towards Green Packaging: The Current Status and Future Outlook for Polyesters in the Packaging Industry. Green Chem. 2017, 19 (20), 4737-4753. https://doi.org/DOI: 10.1039/C7GC02521A.

(26) Ma, S.; Liu, C.; Sablong, R. J.; Noordover, B. A. J.; Hensen, E. J. M.; Van Benthem, R. A. T. M.; Koning, C. E. Catalysts for Isocyanate-Free Polyurea Synthesis: Mechanism and $\begin{array}{llllll}\text { Application. } & \text { ACS } & \text { Catal. } & \text { 2016, } & 6 & \text { (10), }\end{array}$ https://doi.org/10.1021/acscatal.6b01673.

(27) Tang, D.; Mulder, D. J.; Noordover, B. A. J.; Koning, C. E. Well-Defined Biobased Segmented Polyureas Synthesis via a TBD-Catalyzed Isocyanate-Free Route. Macromol. Rapid Commun. 2011, 32 (17), 1379-1385. https://doi.org/10.1002/marc.201100223.

(28) Dabral, S.; Schaub, T. The Use of Carbon Dioxide (CO2) as a Building Block in Organic Synthesis from an Industrial Perspective. Adv. Synth. Catal. 2019, 361 (2), 223-246. https://doi.org/10.1002/adsc.201801215.

(29) Hu, J.; Ma, J.; Zhu, Q.; Qian, Q.; Han, H.; Mei, Q.; Han, B. Zinc(II)-Catalyzed Reactions of Carbon Dioxide and Propargylic Alcohols to Carbonates at Room Temperature. Green Chem. 2016, 18 (2), 382-385. https://doi.org/10.1039/c5gc01870f.

(30) Qiu, J.; Zhao, Y.; Li, Z.; Wang, H.; Fan, M.; Wang, J. Efficient Ionic-Liquid-Promoted Chemical Fixation of CO2into A-Alkylidene Cyclic Carbonates. ChemSusChem 2017, 10 (6), 1120-1127. https://doi.org/10.1002/cssc.201601129. 
(31) Song, Q. W.; Yu, B.; Li, X. D.; Ma, R.; Diao, Z. F.; Li, R. G.; Li, W.; He, L. N. Efficient Chemical Fixation of CO2promoted by a Bifunctional Ag2WO4/Ph3P System. Green Chem. 2014, 16 (3), 1633-1638. https://doi.org/10.1039/c3gc42406e.

(32) Song, Q. W.; He, L. N. Robust Silver(I) Catalyst for the Carboxylative Cyclization of Propargylic Alcohols with Carbon Dioxide under Ambient Conditions. Adv. Synth. Catal. 2016, 358 (8), 1251-1258. https://doi.org/10.1002/adsc.201500639.

(33) Gu, Y.; Shi, F.; Deng, Y. Ionic Liquid as an Efficient Promoting Medium for Fixation of CO 2: Clean Synthesis of $\alpha$-Methylene Cyclic Carbonates from CO2 and Propargyl Alcohols Catalyzed by Metal Salts under Mild Conditions. J. Org. Chem. 2004, 69 (2), 391-394. https://doi.org/10.1021/jo0351365.

(34) Falbe, J.; Bahrmann, H.; Lipps, W.; Mayer, D.; Frey, G. D. Alcohols , Aliphatic. Ullmann's Encyclopedia of Industrial Chemistry; Wiley-VCH Verlag GmbH \& Co. KGaA, 2013; pp 1-26. https://doi.org/10.1002/14356007.a01_279.pub2.

(35) Magliozzi, F.; Chollet, G.; Grau, E.; Cramail, H. Benefit of the Reactive Extrusion in the Course of Polyhydroxyurethanes Synthesis by Aminolysis of Cyclic Carbonates. ACS

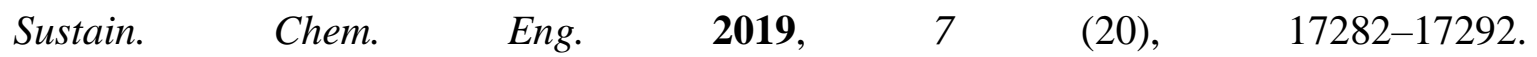
https://doi.org/10.1021/acssuschemeng.9b04098.

(36) Song, Q. W.; Chen, W. Q.; Ma, R.; Yu, A.; Li, Q. Y.; Chang, Y.; He, L. N. Bifunctional Silver(I) Complex-Catalyzed CO2 Conversion at Ambient Conditions: Synthesis of $\alpha$ Methylene Cyclic Carbonates and Derivatives. ChemSusChem 2015, 8 (5), 821-827. https://doi.org/10.1002/cssc.201402921. 
Qi, C. R.; Jiang, H. F. Efficient Synthesis of $\beta$-Oxopropylcarbamates in Compressed CO2 without Any Additional Catalyst and Solvent. Green Chem. 2007, 9 (12), 1284-1286. https://doi.org/10.1039/b707893e.

(38) Joumier, J. M.; Bruneau, C.; Dixneuf, P. H. Direct Access to $\beta$-Oxopropyl Carbonates from Bulky Alcohols. J. Chem. Soc., Perkin Trans. 1 1993, 50 (15), 1749-1751. https://doi.org/10.1039/P19930001749.

(39) Hu, J.; Ma, J.; Lu, L.; Qian, Q.; Zhang, Z.; Xie, C.; Han, B. Synthesis of Asymmetrical Organic Carbonates Using CO2as a Feedstock in $\mathrm{AgCl} / \mathrm{Ionic}$ Liquid System at Ambient $\begin{array}{lllll}\text { Conditions. } & \text { ChemSusChem } & \text { 2017, } & 10 & \text { (6), 1292-1297. }\end{array}$ https://doi.org/10.1002/cssc.201601773.

(40) Gennen, S.; Grignard, B.; Tassaing, T.; Christine, J.; Detrembleur, C. Polymers CO2 Sourced $\alpha$-Alkylidene Cyclic Carbonates: A Step Forward in the Quest for Functional Regioregular Poly(Urethane)s and Poly(Carbonate)s. Angew. Chem. Int. Ed. 2017, 56, 10394-10398. https://doi.org/10.1002/anie.201704467.

(41) Ouhib, F.; Grignard, B.; Van Den Broeck, E.; Luxen, A.; Robeyns, K.; Van Speybroeck, V.; Jerome, C.; Detrembleur, C. A Switchable Domino Process for the Construction of Novel CO2-Sourced Sulfur-Containing Building Blocks and Polymers. Angew. Chem. Int. Ed. 2019, 58 (34), 11768-11773. https://doi.org/10.1002/anie.201905969.

Ouhib, F.; Meabe, L.; Mahmoud, A.; Eshraghi, N.; Grignard, B.; Thomassin, J.; Aqil, A.; Boschini, F.; Jérôme, C.; Mecerreyes, D.; et al. CO2-Sourced Polycarbonates as Solid Electrolytes for Room Temperature Operating Lithium Batteries. J. Mater. Chem. A 2019, 
No. 7, 9844-9853. https://doi.org/10.1039/c9ta01564g.

(43) Ouhib, F.; Meabe, L.; Mahmoud, A.; Grignard, B.; Thomassin, J.-M.; Boschini, F.; Zhu, H.; Forsyth, M.; Mecerreyes, D.; Detrembleur, C. Influence of the Cyclic versus Linear Carbonate Segments in the Properties and Performance of CO2-Sourced Polymer Electrolytes for Lithium Batteries. ACS Appl. Polym. Mater. 2020, 2 (2), 922-931. https://doi.org/10.1021/acsapm.9b01130.

(44) Nakano, K.; Kamada, T.; Nozaki, K. Selective Formation of Polycarbonate over Cyclic Carbonate: Copolymerization of Epoxides with Carbon Dioxide Catalyzed by a Cobalt(III) Complex with a Piperidinium End-Capping Arm. Angew. Chem. Int. Ed. 2006, 45 (43), 7274-7277. https://doi.org/10.1002/anie.200603132.

(45) Poland, S. J.; Darensbourg, D. J. A Quest for Polycarbonates Provided: Via Sustainable Epoxide/CO2 Copolymerization Processes. Green Chem. 2017, 19 (21), 4990-5011. https://doi.org/10.1039/c7gc02560b.

(46) Allen, S. D.; Moore, D. R.; Lobkovsky, E. B.; Coates, G. W. High-Activity, Single-Site Catalysts for the Alternating Copolymerization of $\mathrm{CO} 2$ and Propylene Oxide. J. Am. Chem. Soc. 2002, 124 (48), 14284-14285. https://doi.org/10.1021/ja028071g.

(47) Inoue, S.; Koinuma, H.; Tsuruta, T. Copolymerization of Carbon Dioxide and Epoxide. Polym. Lett. 1969, 7, 287-292. https://doi.org/10.1002/pol.1969.110070408

(48) Dabral, S.; Licht, U.; Rudolf, P.; Bollmann, G.; Stephen, A.; Hashmi, K.; Schaub, T. Synthesis and Polymerisation of $\alpha$-Alkylidene Cyclic Carbonates Obtained from Carbon Dioxide, Epoxides and the Primary Propargylic Alcohol 1,4-Butynediol. Green Chem. 
2020. 22, 1553-1558. https://doi.org/10.1039/C9GC04320A.

(49) Song, D.; Li, D.; Xiao, X.; Cheng, C.; Chaemchuen, S.; Yuan, Y.; Verpoort, F. Synthesis of $\beta$-Oxopropylcarbamates in a Recyclable AgBr/Ionic Liquid Catalytic System: An Efficient Assembly of CO2 under Ambient Pressure. J. CO2 Util. 2018, 27, 217-222. https://doi.org/10.1016/j.jcou.2018.07.021.

(50) Song, Q. W.; Liu, P.; Han, L. H.; Zhang, K.; He, L. N. Upgrading CO2 by Incorporation into Urethanes through Silver-Catalyzed One-Pot Stepwise Amidation Reaction. Chinese J. Chem. 2018, 36 (2), 147-152. https://doi.org/10.1002/cjoc.201700572.

(51) Qi, C.; Huang, L.; Jiang, H. Efficient Synthesis of $\beta$-Oxoalkyl Carbamates from Carbon Dioxide, Internal Propargylic Alcohols, and Secondary Amines Catalyzed by Silver Salts and DBU. Synthesis. 2010, No. 9, 1433-1440. https://doi.org/10.1055/s-0029-1218675.

(52) Zhao, Q.-N.; Song, Q.-W.; Liu, P.; Zhang, K.; Hao, J. Ag(I)/(C2H5)4 NCl Cooperation Catalysis for Fixing $\mathrm{CO} 2$ or Its Derivatives into $\beta$-Oxopropylcarbamates. ChemistrySelect 2018, 3 (24), 6897-6901. https://doi.org/10.1002/slct.201801422.

(53) Song, Q. W.; Zhou, Z. H.; Yin, H.; He, L. N. Silver(I)-Catalyzed Synthesis of $\beta$ Oxopropylcarbamates from Propargylic Alcohols and CO2 Surrogate: A Gas-Free $\begin{array}{lllll}\text { Process. } & \text { ChemSusChem } & \text { 2015, } & 8 & \text { (23), }\end{array}$ https://doi.org/10.1002/cssc.201501176.

(54) Zhou, Z.; Xia, S.; He, L. Green Catalysis for Three-Component Reaction of Carbon Dioxide, Propargylic Alcohols and Nucleophiles. Wuli Huaxue Xuebao/ Acta Phys. Chim. Sin. 2018, 34 (8), 838-844. https://doi.org/10.3866/PKU.WHXB201712271. 
(55) Song, Q.-W.; Zhao, Q.-N.; Li, J.-Y.; Zhang, K.; Liu, P. Selective Conversion of CO2 and Switchable Alcohols into Linear or Cyclic Carbonates via Versatile Zinc Catalysis. Synthesis. 2019, 51 (03), 739-746. https://doi.org/10.1055/s-0037-1611058.

(56) Zhou, Z.-H.; Song, Q.-W.; Xie, J.-N.; Ma, R.; He, L. Silver(I)-Catalyzed ThreeComponent Reaction of Propargylic Alcohols, $\mathrm{CO} 2$ and Monohydric Alcohols: Thermodynamically Feasible Access to $\beta$-Oxopropyl Carbonates. Chem. - An Asian J. 2016, 11 (14), 2065-2071.

Li, J.; Song, Q.; Zhang, H.; Liu, P.; Zhang, K.; Wang, J.; Zhang, D. Synergistic $\mathrm{Ag}(\mathrm{I}) / \mathrm{nBu}_{4} \mathrm{NBr}$-Catalyzed Fixation of $\mathrm{CO} 2$ to $\beta$-Oxopropyl Carbonates via Propargylic Alcohols and Monohydric Alcohols. Tetrahedron 2019, 75 (15), 2343-2349. https://doi.org/10.1016/j.tet.2019.03.006.

(58) Li, J.-Y.; Han, L.-H.; Xu, Q.-C.; Song, Q.-W.; Liu, P.; Zhang, K. Cascade Strategy for Atmospheric Pressure CO2 Fixation to Cyclic Carbonates via Silver Sulfadiazine and $\mathrm{Et}_{4} \mathrm{NBr}$ Synergistic Catalysis. ACS Sustain. Chem. Eng. 2019, 7 (3), 3378-3388. https://doi.org/10.1021/acssuschemeng.8b05579.

(59) Grignard, B.; Ngassamtounzoua, C.; Gennen, S.; Gilbert, B.; Méreau, R.; Jerome, C.; Tassaing, T.; Detrembleur, C. Boosting the Catalytic Performance of Organic Salts for the Fast and Selective Synthesis of $\alpha$-Alkylidene Cyclic Carbonates from Carbon Dioxide and Propargylic Alcohols. ChemCatChem 2018, $10 \quad$ (12), 2584-2592. https://doi.org/10.1002/cctc.201800063.

(60) Yang, Y.; Fan, H.; Meng, Q.; Zhang, Z.; Yang, G.; Han, B. Ionic Liquid [OMIm][OAc] 
Directly Inducing Oxidation Cleavage of the $\beta$-O-4 Bond of Lignin Model Compounds. Chem. Commun. 2017, 53 (63), 8850-8853. https://doi.org/10.1039/c7cc04209d.

(61) Hu, Y.; Song, J.; Xie, C.; Wu, H.; Jiang, T.; Yang, G.; Han, B. Transformation of CO2 into $\alpha$-Alkylidene Cyclic Carbonates at Room Temperature Cocatalyzed by $\mathrm{CuI}$ and Ionic Liquid with Biomass-Derived Levulinate Anion. ACS Sustain. Chem. Eng. 2019, 7, 5614 5619. https://doi.org/10.1021/acssuschemeng.8b05851.

(62) Dabral, S.; Bayarmagnai, B.; Hermsen, M.; Schießl, J.; Mormul, V.; Hashmi, A. S. K.; Schaub, T. Silver-Catalyzed Carboxylative Cyclization of Primary Propargyl Alcohols $\begin{array}{lllllll}\text { with } & \mathrm{CO} 2 . & \text { Org. } & \text { Lett. } & \mathbf{2 0 1 9}, & 21 & \text { (5), }\end{array}$ https://doi.org/10.1021/acs.orglett.9b00156.

(63) Yuan, Y.; Xie, Y.; Zeng, C.; Song, D.; Chaemchuen, S.; Chen, C.; Verpoort, F. A Recyclable AgI/OAc-Catalytic System for the Efficient Synthesis of a-Alkylidene Cyclic Carbonates: Carbon Dioxide Conversion at Atmospheric Pressure. Green Chem. 2017, 19 (13), 2936-2940. https://doi.org/10.1039/c7gc00276a.

(64) Brege, A.; Méreau, R.; McGehee, K.; Grignard, B.; Detrembleur, C.; Jerome, C.; Tassaing, T. The Coupling of $\mathrm{CO} 2$ with Diols Promoted by Organic Dual Systems: Towards Products Divergence via Benchmarking of the Performance Metrics. J. CO2 Util. 2020, 38, 88-98. https://doi.org/10.1016/j.jcou.2020.01.003.

\section{Synopsis}

This paper treats on the valorization of carbon dioxide and (bio) sourced diols as carbonyl source for the synthesis of oxoalkylcarbonates and polycarbonates 
TOC graphic "for table of content use only"

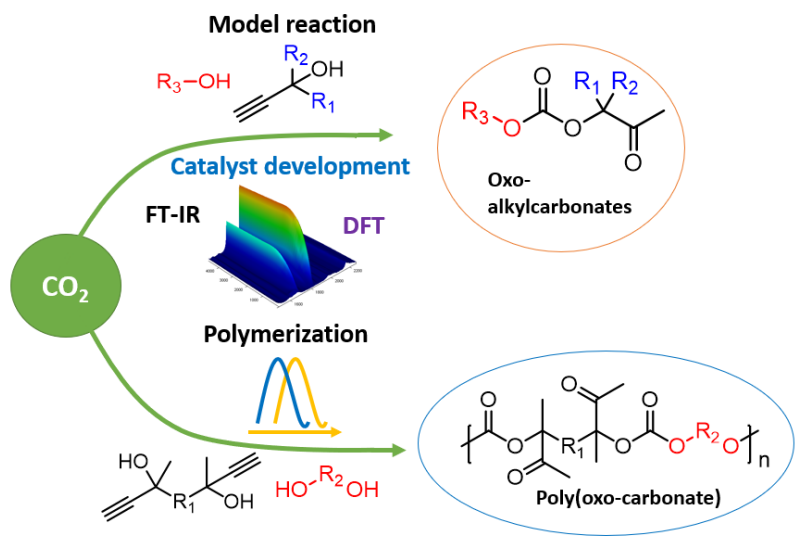

